\title{
Diets for weight management in adults with type 2 diabetes: an umbrella review of published meta-analyses and systematic review of trials of diets for diabetes remission
}

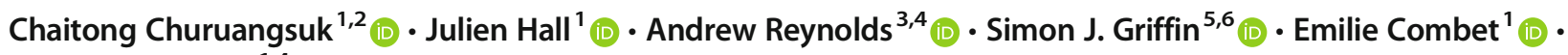 \\ Michael E. J. Lean ${ }^{1,4}$ (D)
}

Received: 20 March 2021 / Accepted: 28 July 2021 / Published online: 17 November 2021

(C) The Author(s) 2021

\begin{abstract}
Aims/hypothesis Weight reduction is fundamental for type 2 diabetes management and remission, but uncertainty exists over which diet type is best to achieve and maintain weight loss. We evaluated dietary approaches for weight loss, and remission, in people with type 2 diabetes to inform practice and clinical guidelines.

Methods First, we conducted a systematic review of published meta-analyses of RCTs of weight-loss diets. We searched MEDLINE (Ovid), PubMed, Web of Science and Cochrane Database of Systematic Reviews, up to 7 May 2021. We synthesised weight loss findings stratified by diet types and assessed meta-analyses quality with A Measurement Tool to Assess Systematic Reviews (AMSTAR) 2. We assessed certainty of pooled results of each meta-analysis using Grading of Recommendations, Assessment, Development and Evaluations (GRADE) (PROSPERO CRD42020169258). Second, we conducted a systematic review of any intervention studies reporting type 2 diabetes remission with weight-loss diets, in MEDLINE (via PubMed), Embase and Cochrane Central Register of Controlled Trials, up to 10 May 2021. Findings were synthesised by diet type and study quality (Cochrane Risk of Bias tool 2.0 and Risk Of Bias In Non-randomised Studies - of Interventions [ROBINS-I]), with GRADE applied (PROSPERO CRD42020208878).

Results We identified 19 meta-analyses of weight-loss diets, involving 2-23 primary trials $(n=100-1587)$, published $2013-$ 2021. Twelve were 'critically low' or 'low' AMSTAR 2 quality, with seven 'high' quality. Greatest weight loss was reported with very low energy diets, 1.7-2.1 MJ/day (400-500 kcal) for 8-12 weeks (high-quality meta-analysis, GRADE low), achieving $6.6 \mathrm{~kg}(95 \% \mathrm{CI}-9.5,-3.7)$ greater weight loss than low-energy diets (4.2-6.3 MJ/day [1000-1500 kcal]). Formula meal replacements (high quality, GRADE moderate) achieved $2.4 \mathrm{~kg}(95 \% \mathrm{CI}-3.3,-1.4)$ greater weight loss over $12-52 \mathrm{weeks}$. Low-carbohydrate diets were no better for weight loss than higher-carbohydrate/low-fat diets (high quality, GRADE high). Highprotein, Mediterranean, high-monounsaturated-fatty-acid, vegetarian and low-glycaemic-index diets all achieved minimal (0.3$2 \mathrm{~kg}$ ) or no difference from control diets (low to critically low quality, GRADE very low/moderate). For type 2 diabetes remission, of 373 records, 16 met inclusion criteria. Remissions at 1 year were reported for a median 54\% of participants in RCTs including initial low-energy total diet replacement (low-risk-of-bias study, GRADE high), and $11 \%$ and $15 \%$ for meal replacements and Mediterranean diets, respectively (some concerns for risk of bias in studies, GRADE moderate/low). For ketogenic/very low-carbohydrate and very low-energy food-based diets, the evidence for remission (20\% and $22 \%$, respectively) has serious and critical risk of bias, and GRADE certainty is very low.

Conclusions/interpretation Published meta-analyses of hypocaloric diets for weight management in people with type 2 diabetes do not support any particular macronutrient profile or style over others. Very low energy diets and formula meal replacement appear the most effective approaches, generally providing less energy than self-administered food-based diets. Programmes including a hypocaloric formula 'total diet replacement' induction phase were most effective for type 2 diabetes remission. Most of the evidence is restricted to 1 year or less. Well-conducted research is needed to assess longer-term impacts on weight, glycaemic control, clinical outcomes and diabetes complications.
\end{abstract}

Michael E. J. Lean

mike.lean@glasgow.ac.uk

Extended author information available on the last page of the article 


\section{Research in context}

\section{What is already known about this subject?}

- Weight reduction is fundamental for good type 2 diabetes management and remission

- Uncertainty exists over which diet approach should be recommended to achieve and maintain weight loss

\section{What is the key question?}

- What dietary approaches are effective for sustained weight loss and remission in people with type 2 diabetes?

\section{What are the new findings?}

- Programmes including very low energy diets and formula meal replacement are the most effective for weight management with type 2 diabetes

- No particular macronutrient profile or style offers advantages over others for weight management

- Programmes with a 'total diet replacement' induction phase were the most effective dietary approach for type 2 diabetes remission (up to $61 \%$ of participants at 1 year)

\section{How might this impact on clinical practice in the foreseeable future?}

- A variety of diet compositions can be used equally effectively for weight management with type 2 diabetes; future research should address ways to provide wide implementation with optimal support in real-life settings for weight loss, prevention of weight regain and remissions, rather than continue to seek subtle differences from macronutrient compositions

Keywords Diet · Evidence-based guidelines $\cdot$ Informed clinical practice $\cdot$ Meta-analysis $\cdot$ Quality assessment $\cdot$ Randomised trial . Remission · Systematic review · Type 2 diabetes $\cdot$ Weight loss

\begin{tabular}{|c|c|}
\hline \multicolumn{2}{|c|}{ Abbreviations } \\
\hline AMSTAR & $\begin{array}{l}\text { A Measurement Tool to Assess Systematic } \\
\text { Reviews }\end{array}$ \\
\hline DiRECT & Diabetes Remission Clinical Trial \\
\hline GRADE & $\begin{array}{l}\text { Grading of Recommendations, Assessment, } \\
\text { Development and Evaluations }\end{array}$ \\
\hline ITT & Intention to treat \\
\hline LCD & Low-carbohydrate diet \\
\hline LFD & Low-fat diet \\
\hline MUFA & Monounsaturated fatty acid \\
\hline NRS & Non-randomised study \\
\hline VLED & Very low energy diet \\
\hline WMD & Weight mean difference \\
\hline
\end{tabular}

\section{Introduction}

Type 2 diabetes has both environmental and genetic contributors, the global epidemic consistently following obesity. Its onset is primarily driven by weight gain to an excessive level for that individual, in a complex disease process involving gut hormones, low-grade inflammation and metabolites, possibly including some from the gut microbiota [1]. Ectopic fat accumulation in liver, pancreas and muscle impairs organ functions, resulting in hyperglycaemia, commonly associated with hypertension and dyslipidaemia $[2,3]$. Type 2 diabetes requires lifelong management, but disabling and life-shortening complications occur despite treatment [4]. Without strategic commitment, internationally, to effective preventive actions, type 2 diabetes will affect 629 million people worldwide by 2045 [5].

Weight loss improves all weight-related risk factors and reduces medication load. During an intensive weight loss programme, or early after bariatric surgery, there are already significant improvements in hepatic and muscle insulin sensitivity, and pancreatic first-phase insulin secretion, with rapid loss of ectopic fat from skeletal muscle and liver $[2,3,6]$. A non-diabetic state can be restored for 2 years for $70-80 \%$ of people with type 2 diabetes by interventions that maintain over $10 \mathrm{~kg}$ weight loss $(36 / 149,24 \%$ of participants in the Diabetes Remission Clinical Trial [DiRECT]) [7], which sustains loss of ectopic fat, reversing the pathophysiology and normalising pancreas morphology [8].

Awareness of the benefits of weight loss for type 2 diabetes is high, but both patients and healthcare practitioners currently 
lack authoritative guidance over diets [9]. Current guidelines state that various dietary strategies may be effective, and stress personalising weight management, to take account of social situations, but do not provide guidance over diet compositions $[9,10]$. Consequently, practice can be led by distorted evidence and claims.

Adhering to any energy-reduced diet will inevitably generate and sustain weight loss, whether defined by restriction of energy, of food groups or of specific nutrients, provided that there is incomplete compensation in energy intake and expenditure. In practice, adherence and weight losses vary widely within the same programme, and comparisons between diets often appear to have conflicting results [11]. Metabolic diversity in response to specific nutrient contents has been postulated, but possibly overwhelmed or confounded by mixed behavioural responses to dietary advice. Unless carefully designed, some diets may achieve negative energy imbalance but lack essential micronutrients $[12,13]$ or introduce adverse health effects through other pathways [14-16]. Furthermore, short-term results may not be sustained, potentially requiring additional behavioural approaches for long-term maintenance. While different strategies may work better for some individuals (or some practitioners) than others, there may be preferred diet compositions to optimise weight control [17].

Guideline development has been difficult because systematic reviews and meta-analyses of diet types, themselves open to bias, have appeared conflicting [11]. To resolve these uncertainties and to inform clinical decision making and guideline development as part of a programme of work to update the EASD dietary recommendations, we conducted an umbrella review, to collate and critically appraise all available systematic reviews with meta-analyses of dietary interventions for weight loss in people with type 2 diabetes. As remission of diabetes is now an important goal for weight management, we also conducted a new systematic review and quality appraisal of published intervention studies of non-surgical dietary approaches for type 2 diabetes remission.

\section{Methods}

\section{Protocol and registration}

This paper focuses on dietary strategies for weight loss and type 2 diabetes remission and includes two systematic reviews: (1) a systematic 'umbrella review' of published meta-analyses of RCTs of diets for weight loss in people with type 2 diabetes (PROSPERO CRD42020169258); (2) a systematic review of any intervention studies which report type 2 diabetes remission (PROSPERO CRD42020208878). Our paper is written in accordance with the Preferred Reporting Items for Systematic Reviews and Meta-Analyses
(PRISMA) 2020 [18] and the Synthesis Without Metaanalysis in systematic reviews: reporting guideline [19].

Detailed methods of both systematic reviews are presented in the electronic supplementary material (ESM) Methods and summarised in Fig. 1. The search strategy is in ESM Table 1.

\section{(1) Umbrella review of published meta-analyses}

We searched MEDLINE (Ovid), PubMed, Web of Science and Cochrane Database of Systematic Reviews, up to 7 May 2021, for eligible meta-analyses of RCTs of dietary advice for weight loss.

Data synthesis Synthesised findings (weight loss and $\mathrm{HbA}_{1 \mathrm{c}}$ ) from each meta-analysis included are grouped by diet type, ranked by overall methodological quality using A Measurement Tool to Assess Systematic Reviews (AMSTAR) 2 (ESM Tables 2, 3) and categorised into four levels: high, moderate, low and critically low. Grading of Recommendations, Assessment, Development and Evaluations (GRADE) evaluates the certainty of evidence of pooled results (ESM Table 4).

Planned analysis of associations between changes in energy intake and weight changes from baseline, to differentiate effects of energy restriction and dietary regimen, proved impossible from the published information.

\section{(2) Systematic review of diets for type 2 diabetes remission}

We searched MEDLINE (via PubMed), Embase and Cochrane Central Register of Controlled Trials, up to 10 May 2021, for any intervention studies reporting type 2 diabetes remission with weight loss dietary advice. We first included RCTs reporting type 2 diabetes remission as the primary outcome, the design most likely to provide trustworthy evidence. However, as few such RCTs have been conducted, we also evaluated non-randomised studies (NRSs) to capture the totality of the evidence for 'best available advice' to inform practice and policy [20]. Cochrane Risk of Bias tool 2.0 [21] and Risk Of Bias In Non-randomised Studies - of Interventions (ROBINS-I) [22] were used for quality assessment of RCTs and NRSs, respectively.

Data synthesis Remission of diabetes was reported as percentage from intention to treat (ITT), including all participants. If only completers were reported, we computed an ITT figure assuming participants lost to follow-up all failed to achieve remission (as in the published RCTs). We summarised effect estimates (e.g., median and interquartile ranges), without performing meta-analysis, due to the limited number and heterogeneity of studies [23]. GRADE assesses the certainty of synthesised findings [24]. 
Fig. 1 Summary of the methodological processes of both systematic reviews. Detailed methods are presented in the ESM Methods. ${ }^{\text {aThese types of NRSs }}$ provided intervention to participants and assessed outcomes at designated specific time points (baseline and at the end of intervention), although they could suffer from selection bias and confounding bias. ${ }^{\mathrm{b}}$ AMSTAR 2 level of quality assessment: high quality - the meta-analysis provides an accurate and comprehensive summary of the results of the available studies that addresses the question of interest; moderate - the meta-analysis has more than one weakness, but no critical flaws. It may provide an accurate summary of the results of the available studies; low - the meta-analysis has a critical flaw and may not provide an accurate and comprehensive summary of the available studies that address the question of interest; or critically low - the meta-analysis has more than one critical flaw and should not be relied on to provide an accurate and comprehensive summary of the available studies. CENTRAL, Cochrane Central Register of Controlled Trials; ROBINS-I, Risk Of Bias In Non-randomised Studies - of Interventions; T2D, type 2 diabetes

\section{Umbrella review of diets for weight loss}

Eligibility criteria

i. Systematic reviews with meta-analyses of RCTs

ii. Compared any type of diets with any control diet or usual/routine care

iii. Adult participants, either sex, with T2D

iv. Provided pooled results on a weight loss outcome (primary outcome) and/or changes in $\mathrm{HbA}_{1 \mathrm{c}}$ (secondary) as mean difference between the two diet interventions, or mean difference from baseline, at any length of follow-up

v. Papers were excluded if the diet intervention (or comparators) included additional components (e.g., drugs, bariatric surgery, exercise, or education)

\section{Search and information source}

Databases (inception to 4 February 2020, updated 07 May 2021)

- Medline (OvidSP)

- PubMed

- Web of Science Core Collection

- Cochrane Database of Systematic Reviews

Free text \& Mesh terms: diet, weight loss or weight reduction, type 2 diabetes, and meta-analysis. Reference lists of included reviews were also searched. Neither search restrictions nor limits were applied. A full search strategy for Medline is available in ESM Table 1

\section{Data extracted from included meta-analyses:}

authors, year, title, population characteristics, definitions of diet interventions and controls, numbers of included trials and numbers of total participants from each meta-analysis, duration of study, pooled results on amount of weight loss and $\mathrm{HbA}_{1 \mathrm{c}}$ and $95 \% \mathrm{Cl}, \mathrm{P}^{2}$ heterogeneity statistic and its $p$ value, publication bias, GRADE recommendation (if available)

\section{Methodological quality assessment}

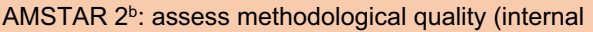
validity) of included meta-analyses (ESM Tables 2 and 3)

\section{Certainty of evidence assessment}

GRADE system: rate the certainty of evidence for pooled results from included meta-analyses
Systematic review of diets for T2D remission

\section{Eligibility criteria}

i. RCTs comparing any type of diet with any control diet or usual/routine care, using either food-based or formula diets

ii. NRSs a as following: (1) non-RCTs; and (2) single arm intervention without control group of any type of diets

iii. Reported proportion/percentage/rate of T2D remission after dietary intervention

iv. Studies were excluded if:

- diet intervention (or comparators) included additional components (e.g., drugs, bariatric surgery, exercise or education)

- observational studies of self-reported dieters, without intervention provided

\section{Search and information source}

Databases (inception to 4 August 2020, updated 10 May 2021)

- Medline (PubMed)

- Embase (OvidSP)

- Cochrane Trial Registry (CENTRAL)

Free texts \& MeSH terms: type 2 diabetes, remission, diet, and intensive lifestyle intervention were used, with Boolean NOT for surgery or bypass in titles and abstracts. Reference lists of included reviews were also searched. Neither search restrictions nor limits were applied. A full search strategy for Embase is available in ESM Table 1

\section{Data extracted from included studies:}

authors, year, title, population characteristics including T2D duration, diet interventions, duration of diets, definition of T2D remission, percentage of remission, amount of weight loss, methods of analysis (whether ITT or completer analysis), dropout and funding agency

\section{Methodological quality assessment}

Cochrane Risk of Bias tool version 2.0: assess methodological quality (internal validity) of included RCTs [21] (ESM Fig. 3)

ROBIN-I: assess methodological quality (internal validity) of included NRSs [22] (ESM Table 17)

Certainty of evidence assessment

GRADE system: rate the certainty of evidence for synthesised evidence from included studies
For the main synthesis, priority was set to RCTs reporting 1 year outcome and low risk of bias. If there was no RCT for a particular diet, synthesis findings were drawn from NRSs with low, followed by high, risk of bias. If both RCTs and NRSs were available for a diet, RCTs were used for synthesised findings and NRSs as supportive evidence [20]. Heterogeneity was explored according to hypothesised effect modifiers: study design, duration of type 2 diabetes and ethnicity.

\section{Results}

\section{(1) Umbrella review of published meta-analyses of RCTs of diets for weight loss and glycaemic control}

Identification of meta-analyses We retrieved 1064 records, including all languages. After removing duplicates, we screened 690 titles and abstracts, and assessed 59 full texts for eligibility. Excluded full texts, with reasons, are shown in ESM Table 5. We included a total of 21 systematic reviews 


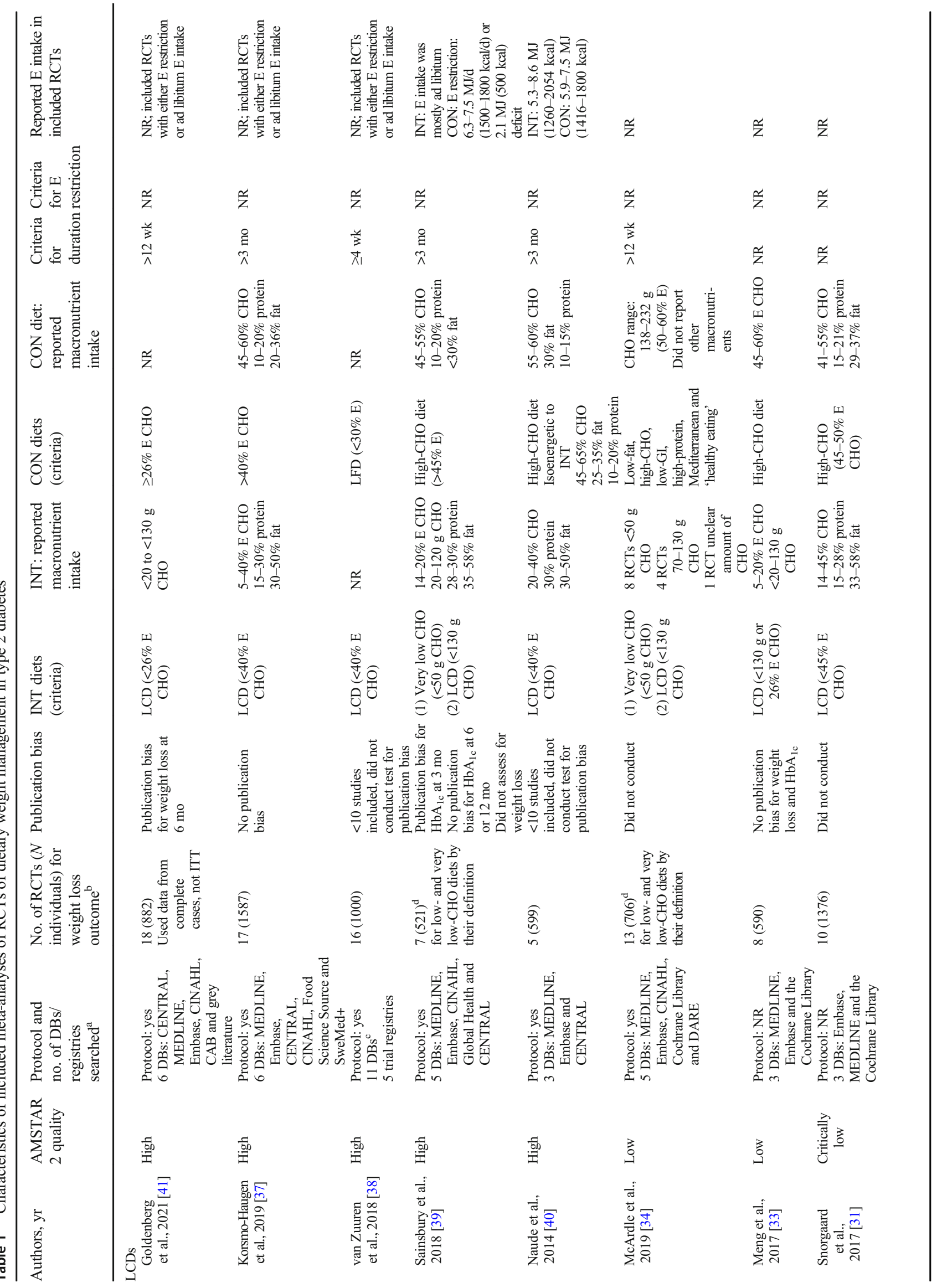




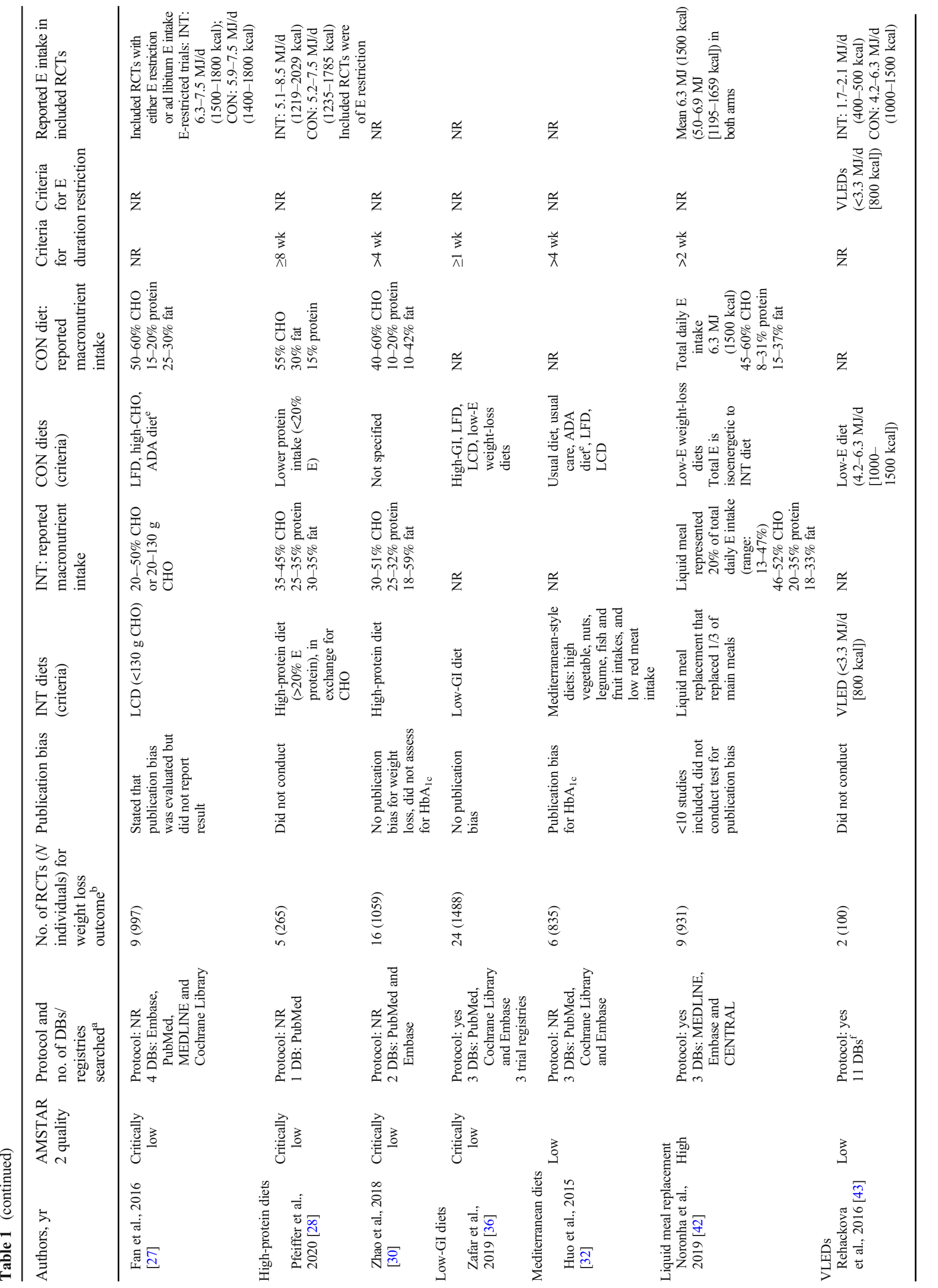




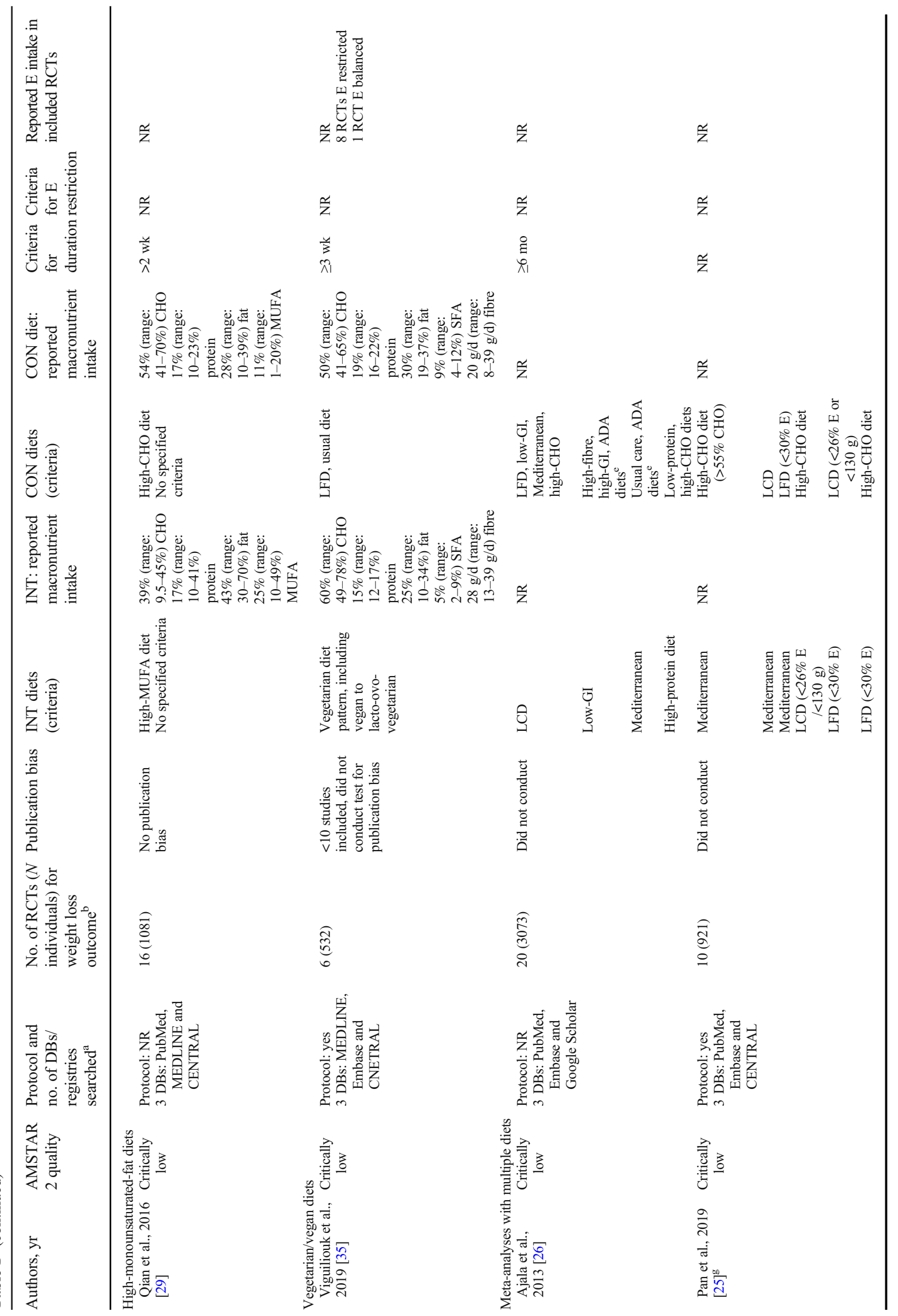




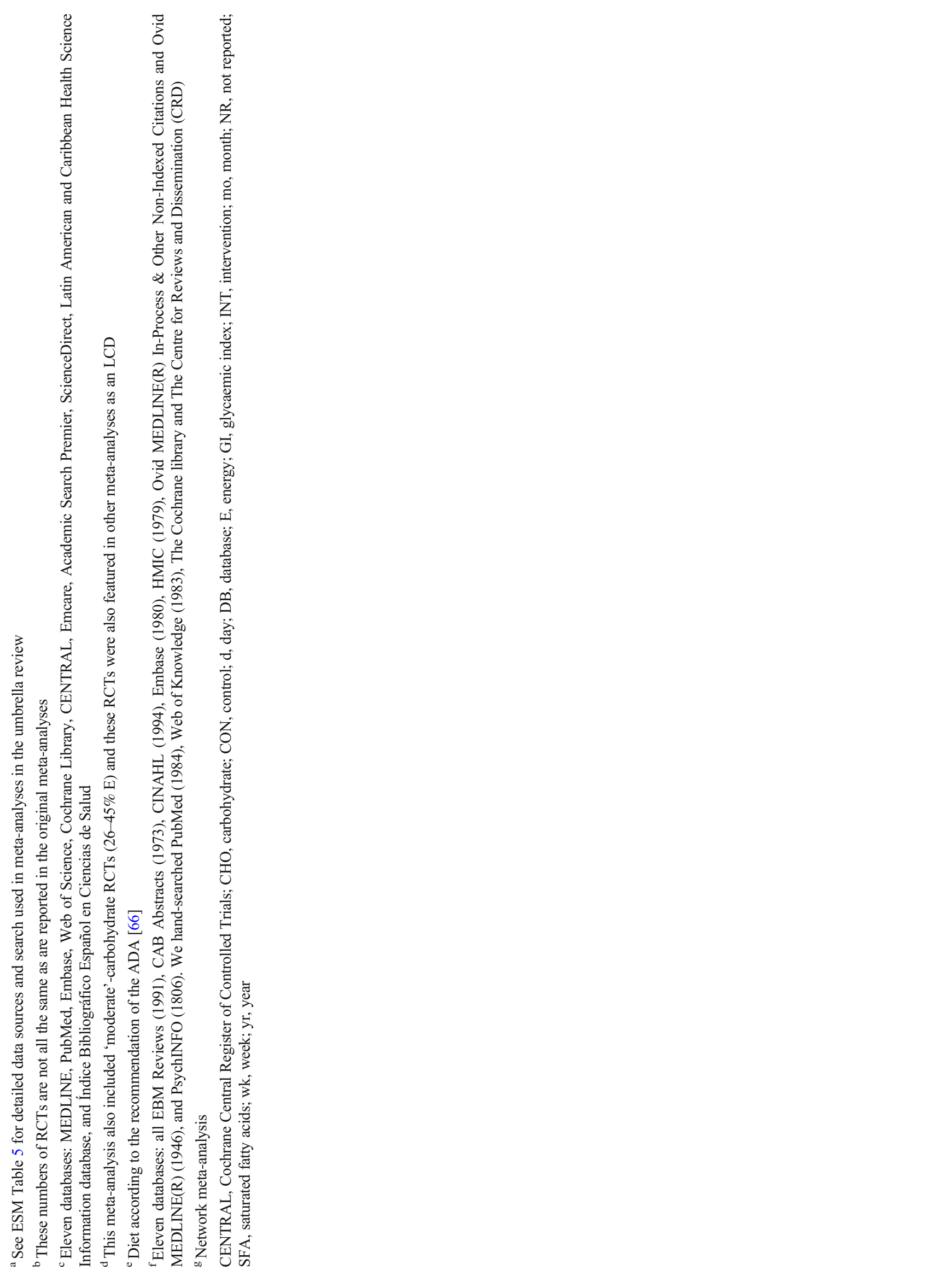


(with 19 meta-analyses) for data synthesis and quality assessment (ESM Fig. 1).

Characteristics of included meta-analyses Of the 19 metaanalyses (Table 1, ESM Table 6), 18 reported direct comparisons of specific diets. Control diets varied, either usual/ routine care or a particular dietary regimen. One metaanalysis used a network method to consider both direct and indirect comparisons between multiple diets (Mediterranean diets, low-carbohydrate diets [LCDs], low-fat diets [LFDs], high-carbohydrate diets and usual diets) [25]. Most metaanalyses were of critically low ( $n=7 ;[25-31])$ to low quality ( $n=5$; [32-36]). Only seven meta-analyses (LCDs, $n=5$ [37-40, 41]; liquid meal replacement, $n=1$ [42]; very low energy diet (VLED), $n=1$ [43]) were assessed as high quality. The ESM Results and ESM Tables 7-10 present methodological quality, heterogeneity and overlaps in source trials of meta-analyses included in the umbrella review.

Dietary advice for weight loss Weight loss outcomes from published meta-analyses are presented in Figs. 2, 3 and ESM Table 11.

LCDs Ten meta-analyses reported on LCDs compared with higher-carbohydrate diets. Not all reported whether source RCTs were ad libitum or hypocaloric prescriptions, with results often pooled from both trial types. Definitions of LCDs varied, including $<130 \mathrm{~g} / \mathrm{day}$, and $<26 \%$ or $<45 \%$ of energy intake from carbohydrate. Duration of interventions ranged from 8 weeks to 4 years.

Four high-quality meta-analyses [37-40] reported that LCDs and higher-carbohydrate diets were equally effective for weight loss, with mean difference ranging between $<1$ and $<2.5 \mathrm{~kg}$, at all durations. GRADE assessment ranged from low to high certainty of evidence. Just one meta-analysis reported greater weight loss with LCD, by $3.5 \mathrm{~kg}$, using complete case data for pooled results [41]. The remaining critically low- to low-quality meta-analyses showed differences of $<1 \mathrm{~kg}$ between the two diets [26, 27, 31, 33, 34].

Very low-carbohydrate diets (21-70 g of carbohydrate daily) showed no greater weight loss than highercarbohydrate diets over durations of 3-36 months (weight mean difference [WMD] $-0.7 \mathrm{~kg} ; 95 \% \mathrm{CI}-2.0,0.7 ; I^{2}=$ $46 \%, p=0.10$ ) in a subgroup analysis [37]. A subgroup analysis of RCTs with low risk of bias reported no difference (WMD $0.9 \mathrm{~kg}$; 95\% CI -1.9, 3.6), while RCTs with high risk of bias showed greater weight loss for LCDs than highercarbohydrate diets (WMD $-1.8 \mathrm{~kg} ; 95 \% \mathrm{CI}-2.8,-0.7$ ) [37].

High-protein diets All meta-analyses $(n=3)$ of high-protein diets were of critically low quality [26, 28, 30]. Critical domains unmet were presence of a review protocol and assessing risk of bias in synthesised findings (ESM Table 3).
Only one provided a definition of 'high protein' ( $>20 \%$ of energy intake), reporting significantly greater weight loss $\left(-1.2 \mathrm{~kg} ; 95 \% \mathrm{CI}-2.17,-0.24 ; I^{2}=5 \%, p=0.38\right)$ than with lower-protein diets ( $<20 \%$ of energy from protein) [28].

Mediterranean diets Two meta-analyses, of low and critically low quality, considered weight loss from Mediterranean diets $[26,32]$. The control interventions combined no diet (usual care) and specified diets, including LFD and LCD. Pooled results indicated significantly greater weight loss with Mediterranean diets than in control groups, by $0.3 \mathrm{~kg}$ (low quality; [32]) to $1.8 \mathrm{~kg}$ (critically low quality; [26]), over durations of 4-24 weeks. A network meta-analysis also reported that Mediterranean diets were marginally more effective than LFDs for weight loss $(-1.2 \mathrm{~kg} ; 95 \% \mathrm{CI}-1.99,-0.37$; four RCTs, low quality; $p$-heterogeneity $=0.08 ; \mathrm{ESM}$ Table 12) [25].

Formula meal replacement One high-quality meta-analysis [42] of nine RCTs including 931 participants reported that replacing one to three main meals daily (replacing 13-47\% of total energy) produced significantly greater weight loss than low-energy diets over $12-52$ weeks $(-2.4 \mathrm{~kg} ; 95 \% \mathrm{CI}$ $-3.3,-1.4 ; I^{2}=84 \%, p<0.001$; GRADE moderate certainty of evidence).

$\boldsymbol{V L E D s}$ One high-quality meta-analysis [43] of two RCTs reported that VLEDs (1.7-2.1 MJ/day for 8-12 weeks) achieved greater weight loss at 3 months $(-6.6 \mathrm{~kg} ; 95 \% \mathrm{CI}$ $\left.-9.5,-3.7 ; I^{2}=58 \%, p=0.12\right)$ and at 6 months $(-5.7 \mathrm{~kg}$; $\left.95 \% \mathrm{CI}-11.1,-0.4 ; I^{2}=58 \%, p=0.12\right)$, compared with an energy-restricted diet (4.2-6.3 MJ/day). These data were from participants who completed the trials.

High-monounsaturated-fatty-acid, vegetarian and lowglycaemic-index diets High-monounsaturated-fatty-acid (MUFA) [29] and vegetarian diets [35] showed greater weight losses, by -1.6 to $-2 \mathrm{~kg}$, than the control diets. Lowglycaemic-index diets $[26,36]$ were not associated with greater weight loss than control diets. Published meta-analyses of these diets were of low to critically low quality.

Intermittent fasting We did a post hoc analysis to evaluate all systematic reviews without meta-analyses (no pooled weight loss; $n=10$ ) that were excluded from our main analysis (as intended protocol). Eight were systematic reviews whose source RCTs were already pooled in meta-analyses identified in this umbrella review. The remaining two systematic reviews compared altered eating patterns with conventional energyrestricted diets (ESM Table 13) [44, 45]. From these two reviews, three RCTs were identified: two for $5: 2$ diets reported no difference in weight loss (high-risk- 


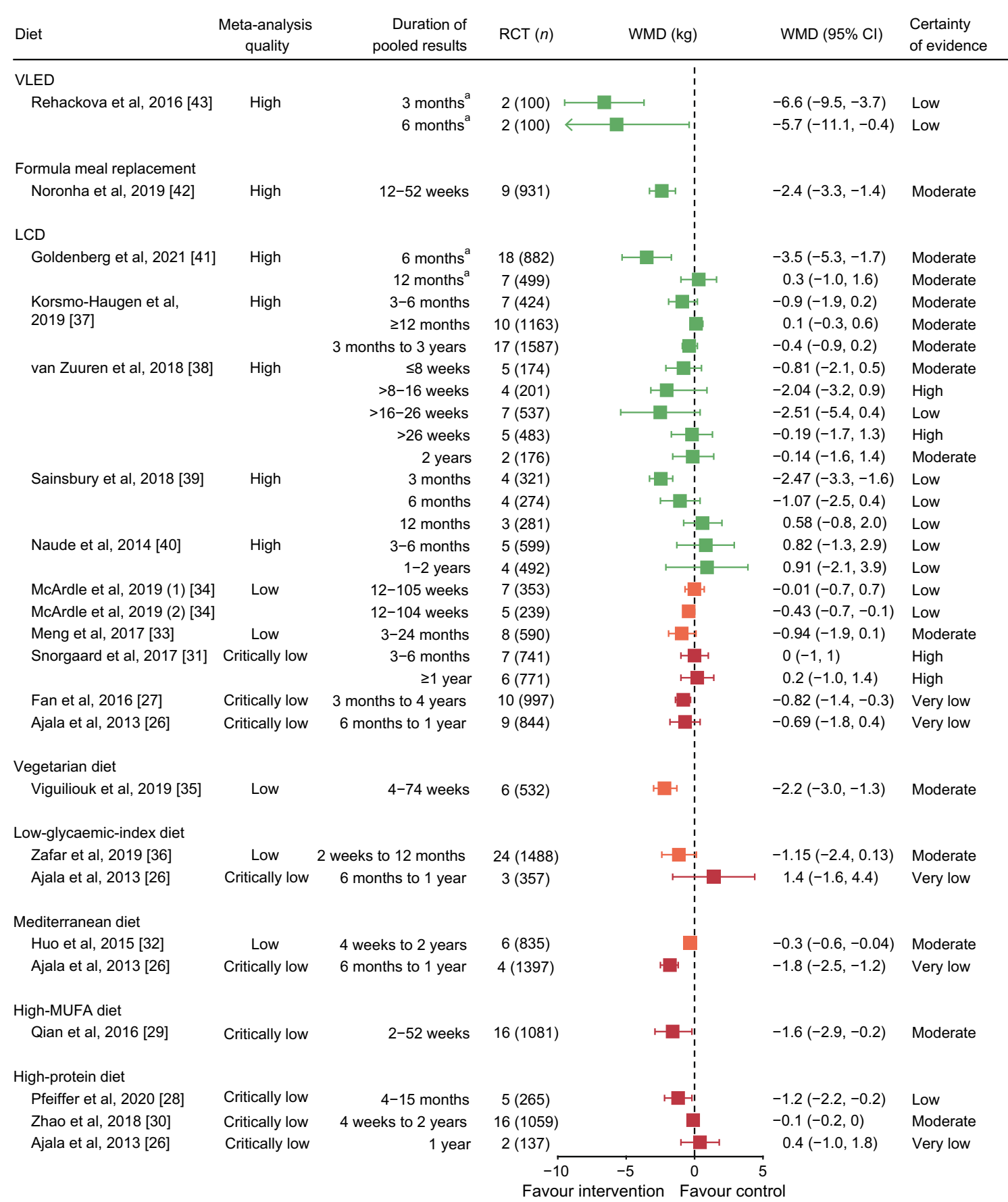

Fig. 2 All published meta-analyses of intervention diets vs control diets on weight loss $(\mathrm{kg})$ stratified by overall quality in each diet type using AMSTAR 2 quality (green, high quality; orange, low quality; red, critically low quality). WMDs are presented alongside 95\% CIs (error bars). Pooled results of McArdle et al., 2019 [34], Fan et al., 2016 [27], Zafar et al., 2019 [36] and Zhao et al., 2018 [30] are standardised mean differ-

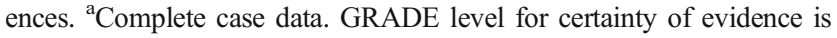
rated as follows: 'high' indicates that we are very confident that the true effect lies close to that of the estimate of the effect; 'moderate' indicates that we are moderately confident in the effect estimate (the true effect is likely to be close to the estimate of the effect, but there is a possibility that it is substantially different); 'low' indicates that our confidence in the effect estimate is limited (the true effect may be substantially different from the estimate of the effect); and 'very low' indicates that we have very little confidence in the effect estimate (the true effect is likely to be substantially different from the estimate of effect) of-bias RCTs) [46, 47], and one for time-restricted dieting reported $1.4 \mathrm{~kg}$ greater weight loss than conventional energy restriction (high-risk-of-bias RCT) [48].
Adherence Some meta-analyses offered assessed dietary adherence separately from weight change. Adherence assessed up to 1 year was poorer with very low- 
carbohydrate diets ( $<50 \mathrm{~g}$ of carbohydrate) than with LCDs $(<130 \mathrm{~g}$ of carbohydrate) $[34,37,40]$, possibly because most of the trials allowed increased carbohydrate intake for later weight loss maintenance. High adherence to VLEDs (up to 6 months), judged from rapid early weight loss and dietary assessment, led to better long-term results [43].

Effects of weight-loss diet intervention on $\mathrm{HbA}_{1 c}$ Among published meta-analyses, $\mathrm{HbA}_{1 \mathrm{c}}$ reduction broadly followed weight loss, and differences between diet types assessed over 3-12 months were small. The published data do not permit an individual-level regression analysis to quantify weight lossindependent effects on $\mathrm{HbA}_{1 \mathrm{c}}$ (ESM Results, ESM Table 14).

\section{(2) Systematic review of intervention studies (either RCTs or NRSs) of diets for remission of type 2 diabetes}

Identification of studies From 373 records identified, we included 16 papers for data synthesis and quality assessment (ESM Fig. 2; excluded studies with reasons in ESM Table 5). These reported on 14 studies (six RCTs, eight NRSs), of seven diet types: total diet replacement $(n=4)$, formula meal replacement $(n=2)$, VLED $(n=2)$, very low-carbohydrate ketogenic diet $(n=1)$, Mediterranean $\operatorname{diet}(n=2), \operatorname{LFD}(n=$ $4)$ and the ADA diet $(n=1)$. Five studies compared diet interventions with usual care according to clinical guidelines, without providing foods or dietary products for participants [49-53]. Among these, three provided diabetes education or advice (Table 2) [49, 50, 52]. Included studies were conducted in Barbados, India, Italy, Qatar, South Africa, Spain,
Thailand, the UK and the USA. Detailed characteristics and methodological quality are in the ESM Results, ESM Tables $15-17$ and ESM Fig. 3.

Definition of type 2 diabetes remission All included studies defined remission as a diagnostic test result, without glucoselowering medication, below the $\mathrm{WHO}$ threshold for diagnosis of type 2 diabetes $\left(\mathrm{HbA}_{1 \mathrm{c}}<48 \mathrm{mmol} / \mathrm{mol}\right.$ [6.5\%], or fasting plasma glucose $<7 \mathrm{mmol} / \mathrm{l}$ ), but they differed in the duration prior to assessment of remission (ESM Tables 15-16). Some studies [54-57] subdivided results as previously proposed by Buse et al. [58]. Glucose-lowering medications were not routinely withdrawn at the beginning of diets in some of the studies, so only minimum remissions can be reported.

Effects of diets on type 2 diabetes remission and weight at 1 year Remission rates and weight changes at 1 year are summarised in Fig. 4 and Table 2, with GRADE certainty of evidence in Table 3.

Programmes that included an induction phase of formula 'total diet replacement' were studied in two RCTs with low risks of bias. Compared with remissions of $4-12 \%$ in wellmatched usual care control arms, the interventions generated median 54\% remission at 12 months from baseline $(N=445$, two RCTs; GRADE high certainty of evidence), with diabetes durations $<6$ or $<2$ years, and mean weight loss of 10 and $12 \mathrm{~kg}$. These two RCTs were designed with remission as the primary outcome $[51,53]$.

Among trials reporting post hoc analyses for remission, one using two meal replacements/day during 0-20 weeks

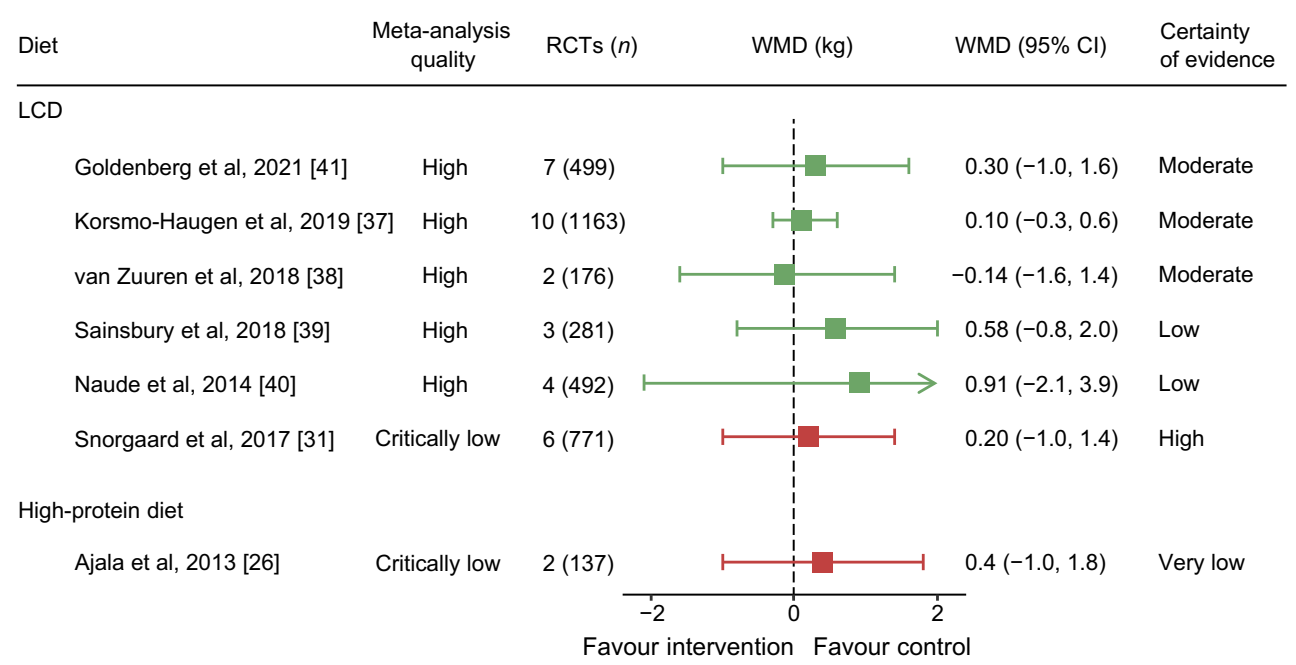

Fig. 3 Meta-analyses with source RCTs of 12 months or longer on weight loss (kg) outcome. WMDs are presented alongside 95\% CIs (error bars). Different colours indicate meta-analysis quality: green, high quality; red, critically low quality. GRADE level for certainty of evidence: 'high' indicates that we are very confident that the true effect lies close to that of the estimate of the effect; 'moderate' indicates that we are moderately confident in the effect estimate (the true effect is likely to be close to

the estimate of the effect, but there is a possibility that it is substantially different); 'low' indicates that our confidence in the effect estimate is limited (the true effect may be substantially different from the estimate of the effect); and 'very low' indicates that we have very little confidence in the effect estimate (the true effect is likely to be substantially different from the estimate of effect) 
and one per day thereafter reported $11 \%$ (247/2157) remission at 1 year (prevalence estimates), with mean weight loss $8.6 \mathrm{~kg}$, compared with $2 \%(43 / 2170)$ in standard care $(N=4503$; GRADE low certainty of evidence), with some concern over risk of bias [49].

A single RCT of Mediterranean diet over 12 months reported a remission prevalence of $15 \%(15 / 102)$, with mean weight loss $6.2 \mathrm{~kg}$, compared with 4\% (4/97) with weight loss $4.2 \mathrm{~kg}$ in the control LFD arm $(N=215$; GRADE low certainty of evidence; some concern over risk of bias) [59].

No RCT has evaluated LCDs/ketogenic diets for type 2 diabetes remission. A non-randomised, controlled study of a very low-carbohydrate (ketogenic) diet reported $20 \%$ remission (52 out of 262 who started treatment [ITT] who had $\mathrm{HbA}_{1 \mathrm{c}}<48 \mathrm{mmol} / \mathrm{mol}$ [6.5\%] without diabetes medication), with mean weight loss $13.8 \mathrm{~kg}$, at 1 year, compared with no remission in a control arm $(N=349$; GRADE very low certainty of evidence; serious risk of bias) [50]. The dropout rate was $17 \%(44 / 262)$ and $22 \%$ had incomplete outcome data. This study primarily focused on $\mathrm{HbA}_{1 \mathrm{c}}$ lowering, not remission, so glucose-lowering medications were not routinely withdrawn.

Another very small uncontrolled study evaluated a 1 week $2.9 \mathrm{MJ} /$ day $(700 \mathrm{kcal})$ food-based diet, finding $22 \%(2 / 9)$ remission at 1 year, with mean weight loss $4.2 \mathrm{~kg}(N=9$, one single-arm intervention; GRADE very low certainty of evidence; critical risk of bias) [60].

Sources of heterogeneity Single-arm intervention studies reported higher remission than RCTs. Participants with shorter type 2 diabetes duration, and Asian ethnicity, were more likely to achieve remission than those with longer type 2 diabetes duration or another ethnicity (Table 2, ESM Tables 15,16).

\section{Discussion}

\section{Dietary weight reduction for people with type 2 diabetes}

This study was conducted to inform practice and policy over dietary advice for weight management of people with type 2 diabetes. It has therefore focused on interventions in freeliving individuals, with a view to long-term management. Based on methodological quality and certainty of the evidence, our umbrella review of meta-analyses found that VLEDs and formula meal replacements produce greater weight losses than conventional low-energy diets. The evidence does not favour LCDs above higher-carbohydrate diets, nor other dietary approaches, i.e., high-protein, Mediterranean, high-MUFA, vegetarian and low-glycaemicindex diets, above control diets. Currently popular intermittent fasting was only captured in systematic reviews without metaanalysis (high-risk-of-bias RCTs) [44, 45]. The evidence, albeit of variable 'quality', is rather consistent such that no one diet type is superior over others for weight management in type 2 diabetes.

While the evidence does not suggest important differences between macronutrient compositions in effectiveness, there may be differences in cost-effectiveness. The evidence on relative cost-effectiveness of weight-loss diet programmes is limited from head-to-head diet comparison trials, but one RCT showed that LCD was not more cost-effective than the standard weight-loss diet [61]. In the Doctor Referral of Overweight People to Low Energy total diet replacement Treatment (DROPLET) trial among people without diabetes, in routine practice, a total diet replacement programme (formula diets) with behavioural support proved more costeffective than nurse-led dietary advice for long-term prevention of obesity-related diseases [62]. For diabetes remission, a total diet replacement programme was estimated to be both more cost-effective and cost-saving than standard care in the DiRECT trial, reflecting reduced need for medications and fewer diabetes complications [63].

Health benefits from weight management depend largely on long-term control of body weight. Most of the evidence cited relates to short-term outcomes, relevant to the initial weight loss induction phase of weight management. Few trials have reported data beyond 12 months, to reflect weight loss maintenance, which may demand different behavioural strategies. One large RCT of high-protein diet suggested benefit for weight loss maintenance, increasing satiety and energy expenditure, albeit for a maintenance phase of only 6 months after completing weight loss [64]. Nutrient-specific effects have been postulated, but are likely to be overwhelmed by variable behavioural responses to dietary advice [65]. Behavioural programmes help to sustain new behaviours, relationships with foods and adherence to dietary advice [66-68]. Consistent evidence is also accruing that long-term weight loss maintenance is better after more rapid early weight loss [69]. Thus, treatments effective for weight loss only in the short term may have long-term value if complemented with a good weight loss maintenance strategy. Practitioners can therefore be confident that a variety of diet types can all achieve the intended weight losses, and potentially remissions of type 2 diabetes, if their patients are able to adhere to the programme sufficiently.

The analyses contradict some popular claims about specific diets: in particular, 'low-carb' diets hold no overall advantage for weight loss when compared with higher-carbohydrate diets. However, we cannot conclude that any individual with type 2 diabetes, in any context, will do equally well with any diet advice, or that a skilled practitioner may not have greater success advising one diet type. The skills and empathy of practitioners may overcome any diet-specific effects on 
weight loss by providing consistent evidence-based support [70]. Realistic trials are required, in which individuals are offered choices, perhaps using $n=1$ randomised trial designs.

\section{Weighing benefits against risks}

Food is fundamental for personal and social wellbeing, and diets can be psychologically testing. Patient preferences, culture, context and lifestyle demand open conversation and shared decision making between practitioners and patients. For either medication or diet, weighing benefits against risks is vital: treatment benefits are often overestimated but harms underestimated [71]. Although all diet types are similarly effective for weight control, health risks were not systematically reported across the studies, and could differ [72]. More rapid early weight loss with more intensive programmes is associated with better longer-term weight outcomes [69], but severe caloric restriction without attention to nutrient content can have unwanted effects. Blood pressure falls with weight loss, and postural hypotension, common in older people and those with diabetes, is aggravated during rapid weight loss if diuretic or antihypertensive drugs are taken concurrently [73]. Hypoglycaemia is possible if hypoglycaemic drugs are also taken [74]. Diets other than nutritionally complete formula diets could incur vitamin and mineral deficiencies [75]. With ketogenic diets, heart failure and neurological problems from thiamine deficiency have been reported [76, 77], as well as reduced intakes of folate, iron and magnesium [12]. Replacing high-carbohydrate foods with red or processed meat (high animal protein and fat) increases sodium and long-chain saturated fat intakes, elevating LDL-cholesterol $[15,16]$ and potentially increasing cardiovascular disease risk [78-80]. High protein intake has been associated with kidney diseases in several observational studies [81]. Metabolic ketoacidosis with ketogenic diets is a hazard, particularly with sodium -glucose cotransporter 2 (SGLT2) inhibitors [82-87]. Meanwhile, extreme fat avoidance provokes cholelithiasis [88].

\section{Remission of type 2 diabetes}

Current evidence on diets for type 2 diabetes remission is more limited. Only two RCTs had remission as the prespecified outcome, both relatively large and using almost identical designs and diets, with very similar results, but in very different populations, notably with different durations of diabetes $[51,53,89]$. A large majority can achieve remission if they maintain sufficient weight loss.

NRSs (non-RCT, single-arm intervention) reported remission rates ranging from $3 \%$ to $75 \%$ by ITT, over various follow-up durations. The highest remission rates, up to $75 \%$, were in people with newly diagnosed diabetes or with $<2$ years of type 2 diabetes duration. Much lower 20-22\% remissions were reported with longer type 2 diabetes duration ( 8 years) or a very brief diet period (1 week). However, these studies did not all fully ascertain remission status, and they had critical risks of bias due to lack of comparator groups and/or randomisation. NRSs reflect performance among those who select and can adhere to a particular diet, and so usually reported better results than those featuring random assignment. In some cases, remission rates were reported for completers only, rather than using the ITT population to properly guide healthcare practice and policy. Despite extracting baseline data for ITT analysis, residual bias/confounding may remain with these study designs.

The main contributor to $\mathrm{HbA}_{1 \mathrm{c}}$ reduction and remission appears to be weight loss, irrespective of diet type. From the high-quality studies with high GRADE certainty, structured programmes with an intensive induction phase with total diet replacement were effective. Remission of diabetes occurs when a patient no longer satisfies the diagnostic criteria, without receiving glucose-lowering medication. To ascertain remission for those already prescribed glucose-lowering drugs, a therapeutic trial of withdrawing medication is necessary, with an appropriate protocol for re-introduction if necessary. Confirmation over a defined duration (e.g., 6 or 12 months) will be required for re-classifying individuals, and for legal or insurance purposes. The diagnostic $\mathrm{HbA}_{1 \mathrm{c}}$ cut-off for diabetes of $48 \mathrm{mmol} / \mathrm{mol}$ (6.5\%) was defined by WHO as broadly the level where diabetes-specific microvascular complications start to emerge [90, 91]. However, many people in remission from type 2 diabetes remain in the prediabetes range of $\mathrm{HbA}_{1 \mathrm{c}}$, where cardiovascular disease risk begins to rise $[92,93]$. Lowering $\mathrm{HbA}_{1 \mathrm{c}}$ to very low levels with multiple medications among people with longstanding disease is associated with increased mortality rate, possibly by relative hypoglycaemia provoking arrythmias [94]. No such concerns have been reported in the small numbers who achieved and sustained $\mathrm{HbA}_{1 \mathrm{c}}<42 \mathrm{mmol} / \mathrm{mol}(<6.0 \%)$ from diet restriction [89].

Most type 2 diabetes is treated in primary care, the setting for both published remission trials using an intensive 'total diet replacement' induction phase with formula diets [51]. Simpler food-based programmes may be effective. A service evaluation from one UK general practice reported weight loss and remission in 59 out of 128 patients who opted for, and persisted with, LCD advice for a mean 23 months [95]. This completers' analysis omits information about numbers who declined the diet, who started but failed to persist and who did not provide outcome data at designated times. The LCD was routinely offered since 2013, and the total number of patients with type 2 diabetes was 473 at the time of evaluation, so these data imply that $12.5 \%$ of the practice achieved remission [95]. A population-based cohort study from 49 general practices in the UK (the Anglo-Danish-Dutch Study of Intensive Treatment in People with Screen-Detected Diabetes in Primary Care [ADDITION-Cambridge]) included 


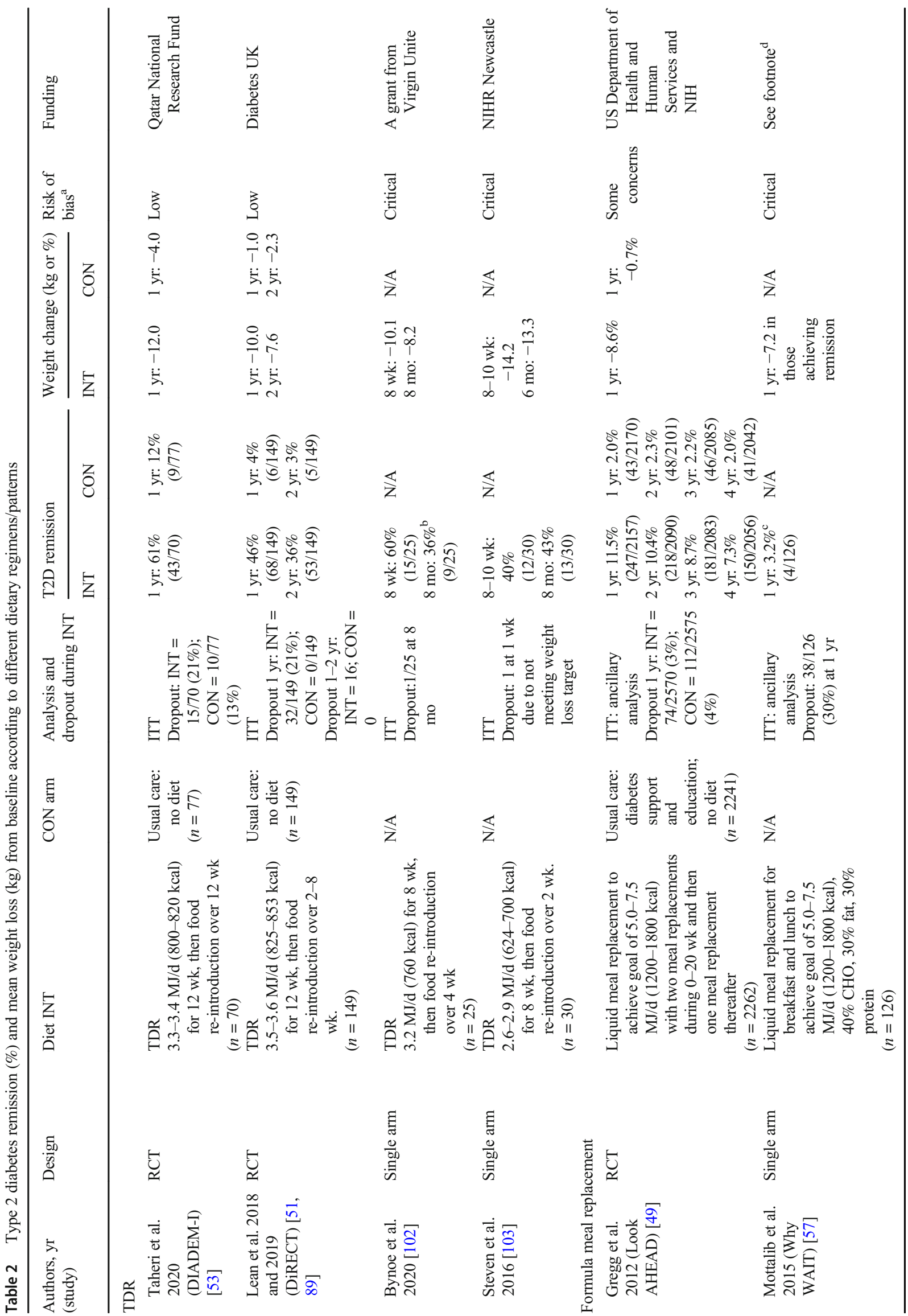




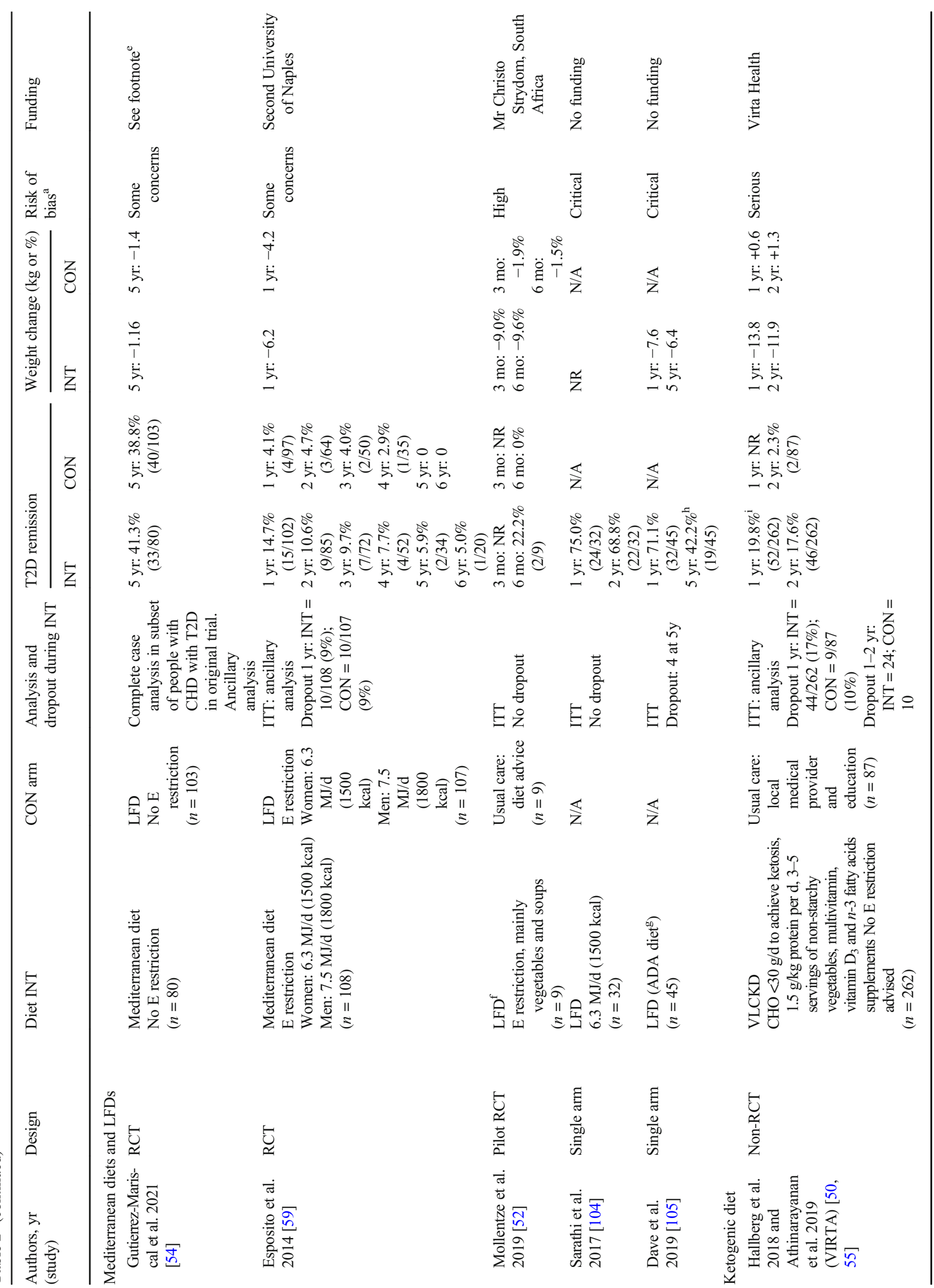




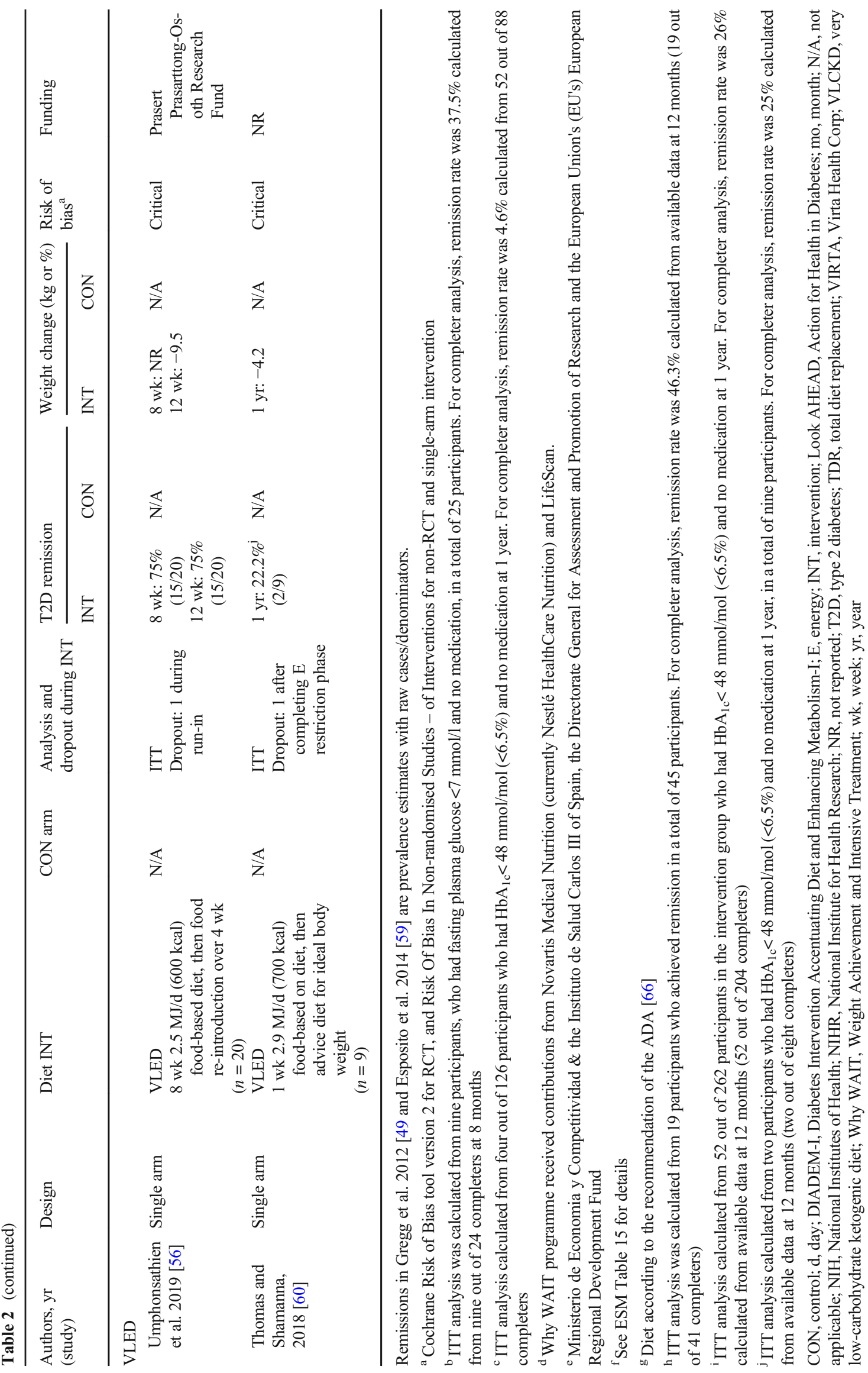


Table 3 Summary of findings of type 2 diabetes remission at 1 year after diet intervention compared with baseline with GRADE certainty of a body of evidence

\begin{tabular}{|c|c|c|c|c|}
\hline Diet & Conclusion statement & $\begin{array}{l}\text { No. of } \\
\text { participants } \\
\text { (no. of } \\
\text { studies) }\end{array}$ & Certainty in the evidence $^{\mathrm{a}}$ & Comments \\
\hline TDR & $\begin{array}{l}\text { TDR leads to a large increase in T2D } \\
\text { remission by a median of } 54 \% \text { from } \\
\text { baseline (range } 46-61 \% \text { ), when compared } \\
\text { with standard care }(4-12 \%) \text {. }\end{array}$ & $\begin{array}{l}445(2 \\
\text { RCTs })\end{array}$ & $\begin{array}{l}\oplus \oplus \oplus \oplus \\
\mathrm{HIGH}\end{array}$ & $\begin{array}{l}\text { Low-risk-of-bias RCTs, pre-specified } \\
\text { outcomes with power calculation }\end{array}$ \\
\hline $\begin{array}{l}\text { Meal } \\
\text { replacement }\end{array}$ & $\begin{array}{l}\text { Meal replacement likely leads to T2D } \\
\text { remission by } 11 \% \text { from baseline, when } \\
\text { compared with standard care plus diabetes } \\
\text { education }(2 \%) \text {. }\end{array}$ & $\begin{array}{r}4503(1 \\
\mathrm{RCT})\end{array}$ & $\begin{array}{l}\oplus \oplus \bigcirc \\
\text { MODERATE } \\
\text { Due to possible } \\
\quad \text { publication bias }\end{array}$ & Ancillary observational analysis of RCT \\
\hline $\begin{array}{l}\text { Mediterranean } \\
\text { diet }\end{array}$ & $\begin{array}{l}\text { Mediterranean diet may lead to T2D } \\
\text { remission by } 15 \% \text { from baseline, when } \\
\text { compared with LFD ( } 4 \%) \text {. }\end{array}$ & 215 (1 RCT) & $\begin{array}{l}\oplus \oplus \bigcirc \bigcirc \\
\text { LOW } \\
\text { Due to imprecision }{ }^{\mathrm{b}} \text { and } \\
\text { possible publication } \\
\text { bias }\end{array}$ & $\begin{array}{l}\text { Small sample size, and ancillary } \\
\text { observational analysis of RCT }\end{array}$ \\
\hline $\begin{array}{l}\text { Very low } \\
\text { carbohydrate } \\
\text { ketogenic } \\
\text { diet }\end{array}$ & $\begin{array}{l}\text { The evidence is very uncertain about the } \\
\text { effect of ketogenic diet on T2D remission } \\
\text { due to serious risk of bias of the study } \\
\text { methods and imprecision, although one } \\
\text { non-RCT reported a remission rate of } \\
\text { 20\%, compared with no remission in } \\
\text { usual care with diabetes education. }\end{array}$ & $\begin{array}{l}349(1 \\
\text { non-RCT) }\end{array}$ & $\begin{array}{l}\oplus O O O \\
\text { VERY LOW } \\
\text { Due to serious risk of bias } \\
\quad \text { (rated down } 2 \text { levels) } \\
\text { and imprecision }\end{array}$ & $\begin{array}{l}\text { Lack of randomisation, uncontrolled } \\
\text { confounding, selection bias, incomplete } \\
\text { outcome data, possible selective } \\
\text { reporting, imprecision and imbalance } \\
\text { between groups }\end{array}$ \\
\hline $\begin{array}{l}\text { VLED (food } \\
\text { based) }\end{array}$ & $\begin{array}{l}\text { The evidence is very uncertain about the } \\
\text { effect of food-based VLED on T2D } \\
\text { remission, although one small } \\
\text { uncontrolled intervention study reported a } \\
\text { remission rate of } 22 \% \text {. }\end{array}$ & $\begin{array}{l}9 \text { (1 single } \\
\text { group } \\
\text { uncon- } \\
\text { trolled } \\
\text { interven- } \\
\text { tion) }\end{array}$ & $\begin{array}{l}\oplus \bigcirc O \bigcirc \\
\text { VERY LOW } \\
\text { Due to critical risk of bias } \\
\text { (rated down } 3 \text { levels), } \\
\text { imprecision and } \\
\text { potential publication } \\
\text { bias }\end{array}$ & $\begin{array}{l}\text { Lack of randomisation, uncontrolled } \\
\text { confounding, selection bias and selective } \\
\text { reporting of result. Only one positive, } \\
\text { small study }\end{array}$ \\
\hline
\end{tabular}

Remission is defined as either $\mathrm{HbA}_{1 \mathrm{c}}<48 \mathrm{mmol} / \mathrm{mol}(<6.5 \%)$ or fasting plasma glucose $<7 \mathrm{mmol} / 1$ and no glucose-lowering medication

${ }^{a}$ GRADE level for certainty of evidence: 'high' indicates that we are very confident that the true effect lies close to that of the estimate of the effect; 'moderate' indicates that we are moderately confident in the effect estimate (the true effect is likely to be close to the estimate of the effect, but there is a possibility that it is substantially different); 'low' indicates that our confidence in the effect estimate is limited (the true effect may be substantially different from the estimate of the effect); and 'very low' indicates that we have very little confidence in the effect estimate (the true effect is likely to be substantially different from the estimate of effect)

${ }^{\mathrm{b}}$ Rated down one level due to imprecision, as the sample size is less than an optimal information size of 400

T2D, type 2 diabetes; TDR, total diet replacement

867 participants with newly diagnosed type 2 diabetes; after being followed up for 5 years, there was an overall $30 \%$ remission ( $n=257 / 867$; ITT analysis). Loss of $>10 \%$ of baseline body weight in the first year after diagnosis was associated with $70 \%$ higher chance of remission at 5 years [96]. Every $1 \mathrm{~kg}$ of weight loss was associated with $7 \%$ higher chance of remission at 5 years, regardless of specific diet regimens or lifestyle interventions [96]. There is therefore consistent evidence that remission should be attempted as early as possible from diabetes diagnosis $[70,96]$.

\section{Limitations}

AMSTAR 2 assesses the quality of meta-analyses, prioritising critical domains, where errors and bias can impact pooled findings (ESM Table 2). Only one or two flaws can label a meta-analysis 'low' or 'critically low', with some criteria potentially subjective (e.g., adequacy of the literature search; ESM Table 2). In the umbrella review, many meta-analyses were of 'low' and 'critically low' AMSTAR 2 quality, predominantly through 'no protocol reported' (despite clear and sound methods) and no assessment of publication bias. Many meta-analyses had fewer than ten RCTs to permit assessment of publication bias by funnel plot [97]. If AMSTAR 2 criteria are relaxed for protocol reporting and publication bias, the meta-analyses allow some confidence in the consistent findings of little/no difference in weight loss between any diets.

Although the search strategy was wide and not languagerestricted, most studies included European participants; results 


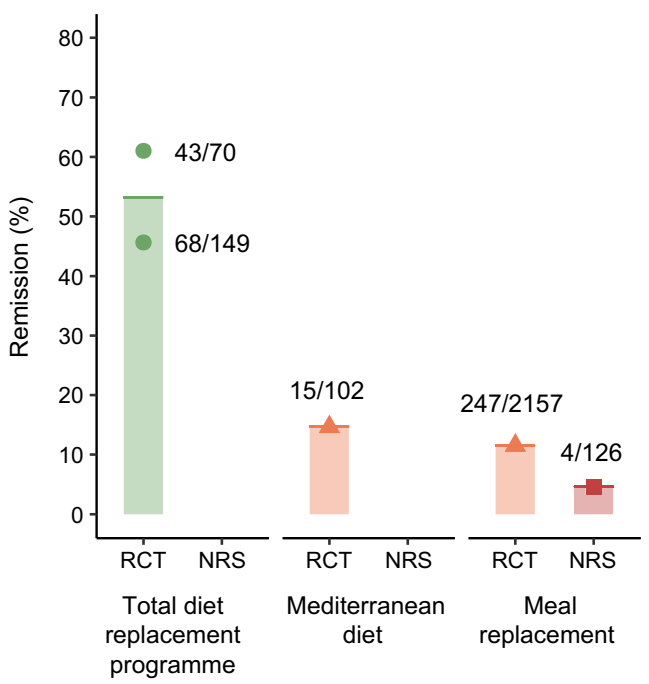

Fig. 4 Percentage of remissions of type 2 diabetes at 12 months after intervention with different diet types, stratified by study design and risk of bias. Each dot, with varying shapes to reflect risk of bias, indicates the data point for each of the studies mentioned in the main text which provided data in this form at 12 months. The column represents the mean for the diet type. Remission was defined as either $\mathrm{HbA}_{1 \mathrm{c}}<48 \mathrm{mmol} / \mathrm{mol}$ $(<6.5 \%)$ or fasting plasma glucose $<7 \mathrm{mmol} / \mathrm{l}$, with no glucose-lowering medication. Total diet replacement programmes included an initial lowenergy formula diet, prescribed for an 8-12 week induction phase,

may not be equally applicable to other ethnic and/or deprived communities. South Asians develop type 2 diabetes at younger ages, more rapidly and with lower BMI, so may be more sensitive to weight loss, with physiological differences in insulin resistance, body composition and fat oxidation $[98,99]$.

The criteria used in the reported meta-analyses and studies focused on specific diet types. However, not all reported sufficient detail about macronutrient or micronutrient contents, or prescribed and reported energy intakes, including energy intake of nutrient-restricted ad libitum diets, which limits interpretation and transferability of results. Control diets used in the meta-analyses and source RCTs also varied, including 'usual' diets in different countries, as well as specified dietary regimens (Table 1). Despite this, differences in weight loss between intervention and control diets, commonly $0-2 \mathrm{~kg}$, are of little clinical significance. Durations of interventions varied: as weight regain is frequent over a longer period, heterogeneity might be expected. However, duration did not introduce heterogeneity, probably because trials with longer follow-up tended to be evaluating more intensive interventions with greater initial weight loss, such that the net weight changes at endpoint are similar to short-term trials.

Given the extent of literature concluding that differences in weight control or $\mathrm{HbA}_{1 \mathrm{c}}$ from different diet compositions are not clinically significant, future trials of similar diet comparisons are unlikely to add useful information. Instead, evidence from clinical practice is needed to identify safe and effective approaches to achieve and maintain weight loss with available skills and training, to assess long-term outcomes from high-

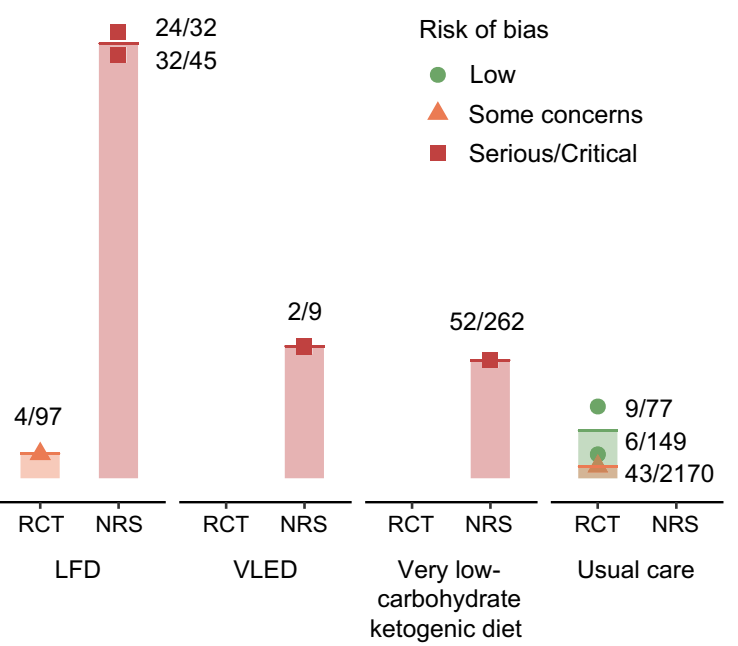

followed by stepped food re-introduction aimed to achieve energy balance for weight loss maintenance. VLED advised a 2.9 MJ (700 kcal) food-based diet for 1 week, then dietary advice for energy intake that matched for ideal body weight. Very low-carbohydrate ketogenic diet was ad libitum intake, carbohydrate $<30 \mathrm{~g} /$ day to achieve ketosis and 3-5 servings of non-starchy vegetables. Usual diet or standard diet interventions included diabetes education support, but no new diet intervention

quality trials and prospective audits of practice with different diets. Interpretating the existing data might be enhanced through individual patient data meta-analysis. Alternatively, the very large amount of work entailed in conducting repeated meta-analyses, and the limitations of different inclusion criteria and detailed methods, support a prospective meta-analysis approach $[100,101]$. All primary studies for inclusion should use an RCT design, with data analyses conducted 'blind'. They should define the intervention clearly (e.g., diets, physical activity, and behavioural and psychological support), and address separately the induction (usually 3-6 months) and maintenance ( $\geq 12$ months) phases of weight management, potentially employing different methods within a treatment programme.

Supplementary Information The online version contains peer-reviewed but unedited supplementary material available at https://oi.org/10.1007/ s00125-021-05577-2.

Acknowledgements The authors thank O. Wu, Director of the National Institute for Health Research (NIHR) Complex Reviews Support Unit (CRSU), University of Glasgow, Glasgow, UK, for providing expert advice on an internal review of the manuscript.

Data availability All data analysed during this work are included in this published article and its ESM file, and in the relevant references.

Funding This research received no specific grant from any funding agency in the public, commercial or not-for-profit sectors.

Authors' relationships and activities $\mathrm{CC}$ is supported by a PhD scholarship from the Prince of Songkla University, Faculty of Medicine, Thailand. JH and AR declare that there are no relationships or activities 
that might bias, or be perceived to bias, their work. SJG is undertaking trials of interventions to promote weight loss and weight loss maintenance for people living with or at risk of diabetes, for which the interventions are provided by WW (Weight Watchers UK). He has received fees from Astra Zeneca and Napp for speaking at educational meetings. The University of Cambridge has received salary support in respect of SJG from the NHS in the East of England through the Clinical Academic Reserve. EC has received funds from Filippo Berio. MEJL has received departmental research support from Diabetes UK, Cambridge Weight Plan and Novo Nordisk, and consultancy fees and support for meeting attendance from Novo Nordisk, Eli Lilly, Merck, Sanofi and Oviva.

Contribution statement CC, EC, AR and MEJL conceptualised the idea, as part of a programme of evidence synthesis conducted by the Nutrition and Diabetes Study Group of the European Association for the Study of Diabetes, to inform new Dietary Guidelines. CC, JH and EC were responsible for the umbrella review of published meta-analyses for weight loss, and the systematic review of trials for diabetes remission. $\mathrm{CC}, \mathrm{JH}, \mathrm{EC}$, $\mathrm{AR}, \mathrm{SJG}$ and MEJL were involved with the interpretation of results. CC wrote the initial draft, with critical revision and comments from JH, AR, SJG, EC and MEJL. All authors approved the submission of the final manuscript. MEJL is responsible for the integrity of the work as a whole.

Open Access This article is licensed under a Creative Commons Attribution 4.0 International License, which permits use, sharing, adaptation, distribution and reproduction in any medium or format, as long as you give appropriate credit to the original author(s) and the source, provide a link to the Creative Commons licence, and indicate if changes were made. The images or other third party material in this article are included in the article's Creative Commons licence, unless indicated otherwise in a credit line to the material. If material is not included in the article's Creative Commons licence and your intended use is not permitted by statutory regulation or exceeds the permitted use, you will need to obtain permission directly from the copyright holder. To view a copy of this licence, visit http://creativecommons.org/licenses/by/4.0/.

\section{References}

1. Kahn SE, Cooper ME, Del Prato S (2014) Pathophysiology and treatment of type 2 diabetes: perspectives on the past, present, and future. Lancet 383(9922):1068-1083. https://doi.org/10.1016/ S0140-6736(13)62154-6

2. Taylor R, Al-Mrabeh A, Zhyzhneuskaya S et al (2018) Remission of human type 2 diabetes requires decrease in liver and pancreas fat content but is dependent upon capacity for beta cell recovery. Cell Metab 28(4):547-556 e543. https://doi.org/10.1016/j.cmet. 2018.07.003

3. Lara-Castro C, Newcomer BR, Rowell J et al (2008) Effects of short-term very low-calorie diet on intramyocellular lipid and insulin sensitivity in nondiabetic and type 2 diabetic subjects. Metabolism 57(1):1-8. https://doi.org/10.1016/j.metabol.2007. 05.008

4. Wright AK, Kontopantelis E, Emsley R et al (2017) Life expectancy and cause-specific mortality in type 2 diabetes: a populationbased cohort study quantifying relationships in ethnic subgroups. Diabetes Care 40(3):338-345. https://doi.org/10.2337/dc16-1616

5. International Diabetes Federation (2017) IDF Diabetes Atlas. Available from www.diabetesatlas.org. Accessed 10 Oct 2019

6. Lim EL, Hollingsworth KG, Aribisala BS, Chen MJ, Mathers JC, Taylor R (2011) Reversal of type 2 diabetes: normalisation of beta cell function in association with decreased pancreas and liver triacylglycerol. Diabetologia 54(10):2506-2514. https://doi.org/ 10.1007/s00125-011-2204-7

7. Thom G, Messow CM, Leslie WS et al (2021) Predictors of type 2 diabetes remission in the diabetes remission clinical trial (DiRECT). Diabet Med 38(8):e14395. https://doi.org/10.1111/ dme. 14395

8. Al-Mrabeh A, Hollingsworth KG, Shaw JAM et al (2020) 2-year remission of type 2 diabetes and pancreas morphology: a post-hoc analysis of the DiRECT open-label, cluster-randomised trial. Lancet Diabetes Endocrinol 8(12):939-948. https://doi.org/10. 1016/S2213-8587(20)30303-X

9. American Diabetes Association (2021) 8. Obesity management for the treatment of type 2 diabetes: standards of medical care in diabetes-2021. Diabetes Care 44(Suppl 1):S100-S110. https://doi. org $/ 10.2337 / \mathrm{dc} 21-\mathrm{S} 008$

10. Dyson PA, Twenefour D, Breen C et al (2018) Diabetes UK evidence-based nutrition guidelines for the prevention and management of diabetes. Diabet Med 35(5):541-547. https://doi. org/10.1111/dme.13603

11. Churuangsuk C, Kherouf M, Combet E, Lean M (2018) Lowcarbohydrate diets for overweight and obesity: a systematic review of the systematic reviews. Obes Rev 19(12):1700-1718. https:// doi.org/10.1111/obr. 12744

12. Churuangsuk C, Griffiths D, Lean MEJ, Combet E (2019) Impacts of carbohydrate-restricted diets on micronutrient intakes and status: a systematic review. Obes Rev 20(8):1132-1147. https:// doi.org/10.1111/obr.12857

13. Pawlak R, Lester SE, Babatunde T (2014) The prevalence of cobalamin deficiency among vegetarians assessed by serum vitamin B12: a review of literature. Eur J Clin Nutr 68(5):541-548. https://doi.org/10.1038/ejen.2014.46

14. Churuangsuk C, Lean MEJ, Combet E (2020) Low and reduced carbohydrate diets: challenges and opportunities for type 2 diabetes management and prevention. Proc Nutr Soc 79(4):498-513. https://doi.org/10.1017/S0029665120000105

15. Chiu S, Williams PT, Krauss RM (2017) Effects of a very high saturated fat diet on LDL particles in adults with atherogenic dyslipidemia: a randomized controlled trial. PLoS One 12(2): e0170664. https://doi.org/10.1371/journal.pone.0170664

16. Elidottir AS, Halldorsson TI, Gunnarsdottir I, Ramel A (2016) Dietary intake and cardiovascular risk factors in Icelanders following voluntarily a low carbohydrate diet. PLoS One 11(8): e0156655. https://doi.org/10.1371/journal.pone.0156655

17. Churuangsuk C, Lean MEJ, Combet E (2020) Carbohydrate knowledge, dietary guideline awareness, motivations and beliefs underlying low-carbohydrate dietary behaviours. Sci Rep 10(1): 14423. https://doi.org/10.1038/s41598-020-70905-2

18. Page MJ, McKenzie JE, Bossuyt PM et al (2021) The PRISMA 2020 statement: an updated guideline for reporting systematic reviews. BMJ 372:n71. https://doi.org/10.1136/bmj.n71

19. Campbell M, McKenzie JE, Sowden A et al (2020) Synthesis without meta-analysis (SWiM) in systematic reviews: reporting guideline. BMJ 368:16890. https://doi.org/10.1136/bmj.16890

20. Schunemann HJ, Tugwell P, Reeves BC et al (2013) Nonrandomized studies as a source of complementary, sequential or replacement evidence for randomized controlled trials in systematic reviews on the effects of interventions. Res Synth Methods 4(1):49-62. https://doi.org/10.1002/jrsm.1078

21. Sterne JAC, Savovic J, Page MJ et al (2019) RoB 2: a revised tool for assessing risk of bias in randomised trials. BMJ 366:14898. https://doi.org/10.1136/bmj.14898

22. Sterne JA, Hernan MA, Reeves BC et al (2016) ROBINS-I: a tool for assessing risk of bias in non-randomised studies of interventions. BMJ 355:i4919. https://doi.org/10.1136/bmj.i4919

23. McKenzie JE, Brennan SE (2020) Chapter 12: Synthesizing and presenting findings using other methods. In: Higgins JPT, Thomas 
J, Chandler J, et al (eds) Cochrane handbook for systematic reviews of interventions 6.1 [updated September 2020]. The Cochrane Collaboration. Available from www.Cochranehandbook.org (or updated version when available: see http:// training.cochrane.org/handbook)

24. Murad MH, Mustafa RA, Schunemann HJ, Sultan S, Santesso N (2017) Rating the certainty in evidence in the absence of a single estimate of effect. Evid Based Med 22(3):85-87. https://doi.org/ 10.1136/ebmed-2017-110668

25. Pan B, Wu Y, Yang Q et al (2019) The impact of major dietary patterns on glycemic control, cardiovascular risk factors, and weight loss in patients with type 2 diabetes: a network meta-analysis. J Evid Based Med 12(1):29-39. https://doi.org/10.1111/ jebm. 12312

26. Ajala O, English P, Pinkney J (2013) Systematic review and metaanalysis of different dietary approaches to the management of type 2 diabetes. Am J Clin Nutr 97(3):505-516. https://doi.org/10. 3945/ajen.112.042457

27. Fan YF, Di HJ, Chen GF, Mao XD, Liu C (2016) Effects of low carbohydrate diets in individuals with type 2 diabetes: systematic review and meta-analysis. Int J Clin Exp Med 9(6):11166-11174

28. Pfeiffer AFH, Pedersen E, Schwab U et al (2020) The effects of different quantities and qualities of protein intake in people with diabetes mellitus. Nutrients 12(2):365. https://doi.org/10.3390/ nu12020365

29. Qian F, Korat AA, Malik V, Hu FB (2016) Metabolic effects of monounsaturated fatty acid-enriched diets compared with carbohydrate or polyunsaturated fatty acid-enriched diets in patients with type 2 diabetes: a systematic review and meta-analysis of randomized controlled trials. Diabetes Care 39(8):1448-1457. https://doi.org/10.2337/dc16-0513

30. Zhao WT, Luo Y, Zhang Y, Zhou Y, Zhao TT (2018) High protein diet is of benefit for patients with type 2 diabetes: an updated meta-analysis. Medicine 97(46):e13149. https://doi.org/ 10.1097/MD.0000000000013149

31. Snorgaard O, Poulsen GM, Andersen HK, Astrup A (2017) Systematic review and meta-analysis of dietary carbohydrate restriction in patients with type 2 diabetes. BMJ Open Diabetes Res Care 5(1):e000354. https://doi.org/10.1136/bmjdrc-2016000354

32. Huo R, Du T, Xu Y et al (2015) Effects of Mediterranean-style diet on glycemic control, weight loss and cardiovascular risk factors among type 2 diabetes individuals: a meta-analysis. Eur J Clin Nutr 69(11):1200-1208. https://doi.org/10.1038/ejen.2014. 243

33. Meng Y, Bai H, Wang S, Li Z, Wang Q, Chen L (2017) Efficacy of low carbohydrate diet for type 2 diabetes mellitus management: a systematic review and meta-analysis of randomized controlled trials. Diabetes Res Clin Pract 131:124-131. https://doi.org/10. 1016/j.diabres.2017.07.006

34. McArdle PD, Greenfield SM, Rilstone SK, Narendran P, Haque MS, Gill PS (2019) Carbohydrate restriction for glycaemic control in type 2 diabetes: a systematic review and meta-analysis. Diabet Med 36(3):335-348. https://doi.org/10.1111/dme.13862

35. Viguiliouk E, Kendall CW, Kahleova H et al (2019) Effect of vegetarian dietary patterns on cardiometabolic risk factors in diabetes: a systematic review and meta-analysis of randomized controlled trials. Clin Nutr 38(3):1133-1145. https://doi.org/10. 1016/j.clnu.2018.05.032

36. Zafar MI, Mills KE, Zheng J et al (2019) Low-glycemic index diets as an intervention for diabetes: a systematic review and meta-analysis. Am J Clin Nutr 110(4):891-902. https://doi.org/ 10.1093/ajen/nqz149

37. Korsmo-Haugen HK, Brurberg KG, Mann J, Aas AM (2019) Carbohydrate quantity in the dietary management of type 2 diabetes: a systematic review and meta-analysis. Diabetes Obes Metab 21(1):15-27. https://doi.org/10.1111/dom.13499

38. van Zuuren EJ, Fedorowicz Z, Kuijpers T, Pijl H (2018) Effects of low-carbohydrate- compared with low-fat-diet interventions on metabolic control in people with type 2 diabetes: a systematic review including GRADE assessments. Am J Clin Nutr 108(2): 300-331. https://doi.org/10.1093/ajen/nqy096

39. Sainsbury E, Kizirian NV, Partridge SR, Gill T, Colagiuri S, Gibson AA (2018) Effect of dietary carbohydrate restriction on glycemic control in adults with diabetes: a systematic review and meta-analysis. Diabetes Res Clin Pract 139:239-252. https://doi. org/10.1016/j.diabres.2018.02.026

40. Naude CE, Schoonees A, Senekal M, Young T, Garner P, Volmink J (2014) Low carbohydrate versus isoenergetic balanced diets for reducing weight and cardiovascular risk: a systematic review and meta-analysis. PLoS One 9(7):e100652. https://doi. org/10.1371/journal.pone.0100652

41. Goldenberg JZ, Day A, Brinkworth GD et al (2021) Efficacy and safety of low and very low carbohydrate diets for type 2 diabetes remission: systematic review and meta-analysis of published and unpublished randomized trial data. BMJ 372:m4743. https://doi. org/10.1136/bmj.m4743

42. Noronha JC, Nishi SK, Braunstein CR et al (2019) The effect of liquid meal replacements on cardiometabolic risk factors in overweight/obese individuals with type 2 diabetes: a systematic review and meta-analysis of randomized controlled trials. Diabetes Care 42(5):767-776. https://doi.org/10.2337/dc18-2270

43. Rehackova L, Arnott B, Araujo-Soares V, Adamson AA, Taylor R, Sniehotta FF (2016) Efficacy and acceptability of very low energy diets in overweight and obese people with type 2 diabetes mellitus: a systematic review with meta-analyses. Diabet Med 33(5):580-591. https://doi.org/10.1111/dme.13005

44. Vitale R, Kim Y (2020) The effects of intermittent fasting on glycemic control and body composition in adults with obesity and type 2 diabetes: a systematic review. Metab Syndr Relat Disord 18(10):450-461. https://doi.org/10.1089/met.2020.0048

45. Welton S, Minty R, O'Driscoll T et al (2020) Intermittent fasting and weight loss: systematic review. Can Fam Physician 66(2): $117-125$

46. Carter S, Clifton PM, Keogh JB (2016) The effects of intermittent compared to continuous energy restriction on glycaemic control in type 2 diabetes; a pragmatic pilot trial. Diabetes Res Clin Pract 122:106-112. https://doi.org/10.1016/j.diabres.2016.10.010

47. Carter S, Clifton PM, Keogh JB (2018) Effect of intermittent compared with continuous energy restricted diet on glycemic control in patients with type 2 diabetes: a randomized noninferiority trial. JAMA Netw Open 1(3):e180756. https://doi.org/10. 1001/jamanetworkopen.2018.0756

48. Kahleova H, Belinova L, Malinska $\mathrm{H}$ et al (2014) Eating two larger meals a day (breakfast and lunch) is more effective than six smaller meals in a reduced-energy regimen for patients with type 2 diabetes: a randomised crossover study. Diabetologia 57(8):1552-1560. https://doi.org/10.1007/s00125-014-3253-5

49. Gregg EW, Chen H, Wagenknecht LE et al (2012) Association of an intensive lifestyle intervention with remission of type 2 diabetes. JAMA 308(23):2489-2496. https://doi.org/10.1001/jama. 2012.67929

50. Hallberg SJ, McKenzie AL, Williams PT et al (2018) Effectiveness and safety of a novel care model for the management of type 2 diabetes at 1 year: an open-label, non-randomized, controlled study. Diabetes Ther 9(2):583-612. https://doi.org/10. 1007/s13300-018-0373-9

51. Lean ME, Leslie WS, Barnes AC et al (2018) Primary care-led weight management for remission of type 2 diabetes (DiRECT): an open-label, cluster-randomised trial. Lancet 391(10120):541551. https://doi.org/10.1016/S0140-6736(17)33102-1 
52. Mollentze WF, Joubert G, Prins A, van der Linde S, Marx GM, Tsie KG (2019) The safety and efficacy of a low-energy diet to induce weight loss, improve metabolic health, and induce diabetes remission in insulin-treated obese men with type 2 diabetes: a pilot RCT. Int J Diabetes Dev C 39(4):618-625. https://doi.org/10. 1007/s13410-019-00734-1

53. Taheri S, Zaghloul H, Chagoury O et al (2020) Effect of intensive lifestyle intervention on bodyweight and glycaemia in early type 2 diabetes (DIADEM-I): an open-label, parallel-group, randomised controlled trial. Lancet Diabetes Endocrinol 8(6):477-489. https:// doi.org/10.1016/S2213-8587(20)30117-0

54. Gutierrez-Mariscal FM, Cardelo MP, de la Cruz S et al (2021) Reduction in circulating advanced glycation end products by Mediterranean diet is associated with increased likelihood of type 2 diabetes remission in patients with coronary heart disease: from the Cordioprev Study. Mol Nutr Food Res 65(1):e1901290. https://doi.org/10.1002/mnfr.201901290

55. Athinarayanan SJ, Adams RN, Hallberg SJ et al (2019) Long-term effects of a novel continuous remote care intervention including nutritional ketosis for the management of type 2 diabetes: a 2-year non-randomized clinical trial. Front Endocrinol (Lausanne) 10: 348. https://doi.org/10.3389/fendo.2019.00348

56. Umphonsathien M, Prutanopajai P, Aiam ORJ et al (2019) Immediate and long-term effects of a very-low-calorie diet on diabetes remission and glycemic control in obese Thai patients with type 2 diabetes mellitus. Food Sci Nutr 7(3):1113-1122. https://doi.org/10.1002/fsn3.956

57. Mottalib A, Sakr M, Shehabeldin M, Hamdy O (2015) Diabetes remission after nonsurgical intensive lifestyle intervention in obese patients with type 2 diabetes. J Diabetes Res 2015: 468704. https://doi.org/10.1155/2015/468704

58. Buse JB, Caprio S, Cefalu WT et al (2009) How do we define cure of diabetes? Diabetes Care 32(11):2133-2135. https://doi.org/10. 2337/dc09-9036

59. Esposito K, Maiorino MI, Petrizzo M, Bellastella G, Giugliano D (2014) The effects of a Mediterranean diet on the need for diabetes drugs and remission of newly diagnosed type 2 diabetes: followup of a randomized trial. Diabetes Care 37(7):1824-1830. https:// doi.org/10.2337/dc13-2899

60. Thomas ND, Shamanna SB (2018) Impact of calorie restriction on glycemic control in overweight patients with type 2 diabetes mellitus. Int J Diabetes Dev C 39(3):547-550. https://doi.org/10. 1007/s13410-018-0706-2

61. Tsai AG, Glick HA, Shera D, Stern L, Samaha FF (2005) Costeffectiveness of a low-carbohydrate diet and a standard diet in severe obesity. Obes Res 13(10):1834-1840. https://doi.org/10. 1038/oby.2005.223

62. Kent S, Aveyard P, Astbury N, Mihaylova B, Jebb SA (2019) Is doctor referral to a low-energy total diet replacement program cost-effective for the routine treatment of obesity? Obesity (Silver Spring) 27(3):391-398. https://doi.org/10.1002/oby.22407

63. Xin Y, Davies A, Briggs A et al (2020) Type 2 diabetes remission: 2 year within-trial and lifetime-horizon cost-effectiveness of the Diabetes Remission Clinical Trial (DiRECT)/Counterweight-Plus weight management programme. Diabetologia 63(10):21122122. https://doi.org/10.1007/s00125-020-05224-2

64. Larsen TM, Dalskov SM, van Baak M et al (2010) Diets with high or low protein content and glycemic index for weight-loss maintenance. N Engl J Med 363(22):2102-2113. https://doi.org/10. 1056/NEJMoa1007137

65. Hall KD, Kahan S (2018) Maintenance of lost weight and longterm management of obesity. Med Clin North Am 102(1):183197. https://doi.org/10.1016/j.mcna.2017.08.012

66. American Diabetes Association (2021) 5. Facilitating behavior change and well-being to improve health outcomes: standards of medical care in diabetes-2021. Diabetes Care 44(Suppl 1):S53S72. https://doi.org/10.2337/dc21-S005

67. Cox CE (2017) Role of physical activity for weight loss and weight maintenance. Diabetes Spectr 30(3):157-160. https://doi. org/10.2337/ds17-0013

68. Ismail K, Winkley K, Rabe-Hesketh S (2004) Systematic review and meta-analysis of randomised controlled trials of psychological interventions to improve glycaemic control in patients with type 2 diabetes. Lancet 363(9421):1589-1597. https://doi.org/10.1016/ S0140-6736(04)16202-8

69. Unick JL, Neiberg RH, Hogan PE et al (2015) Weight change in the first 2 months of a lifestyle intervention predicts weight changes 8 years later. Obesity (Silver Spring) 23(7):1353-1356. https:// doi.org/10.1002/oby.21112

70. Dambha-Miller H, Day A, Kinmonth AL, Griffin SJ (2021) Primary care experience and remission of type 2 diabetes: a population-based prospective cohort study. Fam Pract 38(2): 141-146. https://doi.org/10.1093/fampra/cmaa086

71. Hoffmann TC, Del Mar C (2017) Clinicians' expectations of the benefits and harms of treatments, screening, and tests: a systematic review. JAMA Intern Med 177(3):407-419. https://doi.org/10. 1001/jamainternmed.2016.8254

72. Evert AB, Dennison M, Gardner CD et al (2019) Nutrition therapy for adults with diabetes or prediabetes: a consensus report. Diabetes Care 42(5):731-754. https://doi.org/10.2337/dci19-0014

73. Haywood CJ, Prendergast LA, Lim R, Lappas M, Lim WK, Proietto J (2019) Obesity in older adults: effect of degree of weight loss on cardiovascular markers and medications. Clin Obes 9(4): e12316. https://doi.org/10.1111/cob.12316

74. Leow ZZX, Guelfi KJ, Davis EA, Jones TW, Fournier PA (2018) The glycaemic benefits of a very-low-carbohydrate ketogenic diet in adults with type 1 diabetes mellitus may be opposed by increased hypoglycaemia risk and dyslipidaemia. Diabet Med 35(9):1258-1263. https://doi.org/10.1111/dme.13663

75. Gardner CD, Kim S, Bersamin A et al (2010) Micronutrient quality of weight-loss diets that focus on macronutrients: results from the A TO Z study. Am J Clin Nutr 92(2):304-312. https://doi.org/ 10.3945/ajen.2010.29468

76. Hoyt CS 3rd, Billson FA (1977) Low-carbohydrate diet optic neuropathy. Med J Aust 1(3):65-66. https://doi.org/10.5694/j. 1326-5377.1977.tb130506.x

77. McKenna LA, Drummond RS, Drummond S, Talwar D, Lean ME (2013) Seeing double: the low carb diet. BMJ 346:f2563. https:// doi.org/10.1136/bmj.f2563

78. Ference BA, Ginsberg HN, Graham I et al (2017) Low-density lipoproteins cause atherosclerotic cardiovascular disease. 1. Evidence from genetic, epidemiologic, and clinical studies. A consensus statement from the European Atherosclerosis Society Consensus Panel. Eur Heart J 38(32):2459-2472. https://doi.org/ 10.1093/eurheartj/ehx144

79. Sjogren P, Becker W, Warensjo E et al (2010) Mediterranean and carbohydrate-restricted diets and mortality among elderly men: a cohort study in Sweden. Am J Clin Nutr 92(4):967-974. https:// doi.org/10.3945/ajen.2010.29345

80. Mazidi M, Katsiki N, Mikhailidis DP, Sattar N, Banach M (2019) Lower carbohydrate diets and all-cause and cause-specific mortality: a population-based cohort study and pooling of prospective studies. Eur Heart J 40(34):2870-2879. https://doi.org/10.1093/ eurheartj/ehz174

81. Ko GJ, Rhee CM, Kalantar-Zadeh K, Joshi S (2020) The effects of high-protein diets on kidney health and longevity. J Am Soc Nephrol 31(8):1667-1679. https://doi.org/10.1681/ASN. 2020010028

82. Tougaard NH, Faber J, Eldrup E (2019) Very low carbohydrate diet and SGLT-2-inhibitor: double jeopardy in relation to 
ketoacidosis. BMJ Case Rep 12(4):e227516. https://doi.org/10. 1136/bcr-2018-227516

83. Marzban S, Arbee M, Vorajee N, Richards GA (2020) Nondiabetic ketoacidosis associated with a low carbohydrate, high fat diet in a postpartum lactating female. Oxf Med Case Rep 2020(8):omz026. https://doi.org/10.1093/omcr/omz026

84. Shah P, Isley WL (2006) Ketoacidosis during a low-carbohydrate diet. N Engl J Med 354(1):97-98. https://doi.org/10.1056/ NEJMc052709

85. Shaikh S, Mohamed MM, Mujeeb A, Shaikh F, Harris B (2020) Euglycemic diabetic ketoacidosis precipitated by a keto diet: importance of dietary history in diagnosis. Cureus 12(9):e10199. https://doi.org/10.7759/cureus.10199

86. White-Cotsmire AJ, Healy AM (2020) Ketogenic diet as a trigger for diabetic ketoacidosis in a misdiagnosis of diabetes: a case report. Clin Diabetes 38(3):318-321. https://doi.org/10.2337/ cd20-0001

87. Charoensri S, Sothornwit J, Trirattanapikul A, Pongchaiyakul C (2021) Ketogenic diet-induced diabetic ketoacidosis in a young adult with unrecognized type 1 diabetes. Case Rep Endocrinol 2021:6620832. https://doi.org/10.1155/2021/6620832

88. Festi D, Colecchia A, Orsini M et al (1998) Gallbladder motility and gallstone formation in obese patients following very low calorie diets. Use it (fat) to lose it (well). Int J Obes Relat Metab Disord 22(6):592-600. https://doi.org/10.1038/sj.ijo.0800634

89. Lean MEJ, Leslie WS, Barnes AC et al (2019) Durability of a primary care-led weight-management intervention for remission of type 2 diabetes: 2-year results of the DiRECT open-label, cluster-randomised trial. Lancet Diabetes Endocrinol 7(5):344 355. https://doi.org/10.1016/S2213-8587(19)30068-3

90. The Expert Committee on the Diagnosis and Classification of Diabetes Mellitus (1997) Report of the expert committee on the diagnosis and classification of diabetes mellitus. Diabetes Care 20(7):1183-1197. https://doi.org/10.2337/diacare.20.7.1183

91. Zoungas S, Chalmers J, Ninomiya T et al (2012) Association of $\mathrm{HbAlc}$ levels with vascular complications and death in patients with type 2 diabetes: evidence of glycaemic thresholds. Diabetologia 55(3):636-643. https://doi.org/10.1007/s00125011-2404-1

92. Kleinherenbrink W, Osei E, den Hertog HM, Zandbergen AAM (2018) Prediabetes and macrovascular disease: review of the association, influence on outcome and effect of treatment. Eur J Intern Med 55:6-11. https://doi.org/10.1016/j.ejim.2018.07.001

93. Palladino R, Tabak AG, Khunti K et al (2020) Association between pre-diabetes and microvascular and macrovascular disease in newly diagnosed type 2 diabetes. BMJ Open Diabetes Res Care 8(1):e001061. https://doi.org/10.1136/bmjdrc-2019001061

94. Action to Control Cardiovascular Risk in Diabetes Study Group, Gerstein HC, Miller ME et al (2008) Effects of intensive glucose lowering in type 2 diabetes. N Engl J Med 358(24):2545-2559. https://doi.org/10.1056/NEJMoa0802743
95. Unwin D, Khalid AA, Unwin J et al (2020) Insights from a general practice service evaluation supporting a lower carbohydrate diet in patients with type 2 diabetes mellitus and prediabetes: a secondary analysis of routine clinic data including $\mathrm{HbAlc}$, weight and prescribing over 6 years. BMJ Nutr Prev Health 3(2):285-294. https://doi.org/10.1136/bmjnph-2020-000072

96. Dambha-Miller H, Day AJ, Strelitz J, Irving G, Griffin SJ (2020) Behaviour change, weight loss and remission of type 2 diabetes: a community-based prospective cohort study. Diabet Med 37(4): 681-688. https://doi.org/10.1111/dme.14122

97. Page MJ, Higgins JPT, Sterne JAC (2020) Chapter 13: Assessing risk of bias due to missing results in a synthesis. In: Higgins JPT, Thomas J, Chandler J, et al (eds) Cochrane handbook for systematic reviews of interventions 6.1 [updated September 2020]. The Cochrane Collaboration. Available from www.Cochranehandbook.org (or updated version when available: see http:// training.cochrane.org/handbook)

98. Bhopal RS (2013) A four-stage model explaining the higher risk of type 2 diabetes mellitus in South Asians compared with European populations. Diabet Med 30(1):35-42. https://doi.org/ 10.1111/dme. 12016

99. Hall LM, Moran CN, Milne GR et al (2010) Fat oxidation, fitness and skeletal muscle expression of oxidative/lipid metabolism genes in South Asians: implications for insulin resistance? PLoS One 5(12):e14197. https://doi.org/10.1371/journal.pone.0014197

100. Seidler AL, Hunter KE, Cheyne S, Ghersi D, Berlin JA, Askie L (2019) A guide to prospective meta-analysis. BMJ 367:15342. https://doi.org/10.1136/bmj.15342

101. COMET Initiative (2020) Core Outcome Measures in Effectiveness Trials. Available from www.comet-initiative.org/. Accessed 6 Feb 2021

102. Bynoe K, Unwin N, Taylor C et al (2020) Inducing remission of type 2 diabetes in the Caribbean: findings from a mixed methods feasibility study of a low-calorie liquid diet-based intervention in Barbados. Diabet Med 37(11):1816-1824. https://doi.org/10. 1111/dme.14096

103. Steven S, Hollingsworth KG, Al-Mrabeh A et al (2016) Very lowcalorie diet and 6 months of weight stability in type 2 diabetes: pathophysiological changes in responders and nonresponders. Diabetes Care 39(5):808-815. https://doi.org/10.2337/dc15-1942

104. Sarathi V, Kolly A, Chaithanya HB, Dwarakanath CS (2017) High rates of diabetes reversal in newly diagnosed Asian Indian young adults with type 2 diabetes mellitus with intensive lifestyle therapy. J Nat Sci Biol Med 8(1):60-63. https://doi.org/10.4103/ 0976-9668.198343

105. Dave R, Davis R, Davies JS (2019) The impact of multiple lifestyle interventions on remission of type 2 diabetes mellitus within a clinical setting. Obes Med 13:59-64. https://doi.org/10.1016/j. obmed.2019.01.005

Publisher's note Springer Nature remains neutral with regard to jurisdictional claims in published maps and institutional affiliations. 


\section{Affiliations}

\section{Chaitong Churuangsuk $^{1,2}$ (D) Julien Hall $^{1}$ (D) $\cdot$ Andrew Reynolds ${ }^{3,4}$ (D) Simon J. Griffin $^{5,6}$ (D) Emilie Combet $^{1}$ (D) $\cdot$ Michael E. J. Lean ${ }^{1,4}$ (D)}

1 Human Nutrition, School of Medicine, Dentistry and Nursing, College of Medical, Veterinary and Life Sciences, University of Glasgow, Glasgow, UK

2 Division of Internal Medicine, Faculty of Medicine, Prince of Songkla University, Hat Yai, Thailand

3 Department of Medicine, University of Otago, Dunedin, Otago, New Zealand
4 Edgar National Centre for Diabetes and Obesity Research, University of Otago, Dunedin, Otago, New Zealand

5 MRC Epidemiology Unit, Institute of Metabolic Science, School of Clinical Medicine, University of Cambridge, Cambridge, UK

6 Primary Care Unit, Department of Public Health and Primary Care, School of Clinical Medicine, University of Cambridge, Cambridge, UK 